Evaluation of a phytogenic feed additive on performance, nutrient digestion, and absorption in turkey poults

By:

Charles A. Zumbaugh III

Thesis submitted to the faculty of the Virginia Polytechnic Institute and State University in partial fulfillment of the requirements for the degree of

Master of Science

In

Animal and Poultry Sciences

Committee Members:

Michael E. Persia, Chair

G. Raj Murugesan

Eric A. Wong

December 15, 2017

Blacksburg, VA

Keywords: nutrition, body weight gain, feed efficiency, protein sparing, amino acid. 


\title{
Evaluation of a phytogenic feed additive on performance, nutrient digestion, and absorption in turkey poults
}

\author{
Charles A. Zumbaugh III
}

Scholarly Abstract

In recent years, there has been a growing interest in feeding phytogenic products to poultry for their growth and health benefits. The objective of this experiment was to determine the effects of a phytogenic feed additive on turkey poult performance and digestive physiology over a 6-week brooding period. In total, 864 male Hybrid Converter turkey poults were obtained from a local commercial hatchery on day-of-hatch and placed into floor pens with clean pine shavings. The treatments were randomly assigned including an industry-type corn-soybean meal positive control (PC), a similar diet with a $1.5 \%$ reduction in crude protein and key amino acids (NC), or the NC with the addition of Digestarom ${ }^{\circledR}($ PFA) included at a rate of $1 \mathrm{~g} / \mathrm{kg}$. Body weight gain (BWG), feed intake (FI), feed efficiency (FE), and mortality were recorded throughout the experiment. On day 14 poults fed the PFA had significantly higher BWG compared to the PC and NC fed birds. By day 42 birds fed the PC and PFA diets had significantly higher BWG compared to the NC, and the PC had significantly higher FE compared to the NC and PFA fed birds. No differences in FI or mortality were observed throughout the experiment. There were no significant differences in AMEn, crude protein digestibility, or nutrient transporter or pancreatic enzyme mRNA expression among treatments. However, aminopeptidase activity tended to be lower in the ileum of poults fed the PC or PFA diets compared to the NC, suggesting that the PFA may be improving protein utilization. 


\title{
Evaluation of a phytogenic feed additive on performance, nutrient digestion, and absorption in turkey poults
}

\author{
Charles A. Zumbaugh III
}

\section{Abstract for General Public}

Recent regulations and customer demand have severely restricted the use of antibiotics in poultry production. Historically, antibiotics have been included in poultry diets at sub-therapeutic concentrations to improve performance and reduce disease incidence. Since this restriction, producers have experienced increased feed conversion ratio, decreased body weights, and increases in morbidity and mortality. Not only does this present an animal welfare issue, but producers experience decreased profits due to the decrease in performance associated with restricted antibiotic use. Many researchers are investigating the ability of alternative feed additives to help mitigate the lost performance this restriction has caused. One such alternative is a class of compounds known generally as phytogenic feed additives. These are herbs, spices, and associated products which can be included into the diet at relatively low concentrations. Previous research has demonstrated the ability of phytogenic feed additives to positively influence performance and gastrointestinal tract health, primarily in broiler chickens. Therefore, the objective of this thesis is to investigate the effect of a commercially available phytogenic feed additive on the performance, nutrient digestibility, and absorption in turkey poults over the first six weeks of feeding. Previous indications with this product seem to indicate that it also increases protein utilization so this product was evaluated using a reduced protein diet. By day 14, poults fed the feed additive had significantly higher body weights compared to both the positive and negative control. At the conclusion of the experiment on day 42 , the birds fed the feed additive had significantly higher body weight compared to the negative control and were similar to the positive control. This 
suggests the ability of the feed additive to improve performance when dietary protein is reduced. Data from aminopeptidase activity in the ileum suggest a potential improvement in the efficiency of protein utilization, which may explain the performance improvements when poults were fed the phytogenic feed additive. 


\section{ACKNOWLEDGEMENTS}

I would like to express my sincerest gratitude to my advisor, Dr. Michael Persia, for all of the guidance and opportunities you have provided me throughout my time completing this degree. Your patience and knowledge are something that I strive for not only in this program, but also throughout the rest of my life. I am certain that I would not be where I am today if it were not for everything that you have done for me. I have met countless people through you that have helped to advance my life from a professional and personal standpoint. You have continued to encourage me and push me to be the best that I can be, and I cannot describe how much this means to me. It was a true pleasure to learn from you, and something I will never forget.

I would like to thank my committee members Dr. Eric Wong and Dr. Raj Murugesan for their help and support throughout this program. I greatly appreciate everything I have learned from you, and I would like to thank you for all of the time you have spent teaching me.

Thank you to my friend and Virginia Tech Turkey Farm manager, Dale Shumate, for all of your help. You have taught me a lot about not only growing poultry but also life. All of the long days at the farm seemed to fly by when you were there, and you always had a positive attitude. I will miss working with you and will look back on the time spent working alongside you with a smile.

To Dr. Javier Garcia, I would like to thank you for all of the time you spent teaching me about qPCR and gene expression. You spent a considerable amount of time helping me in the lab and answering my questions, and I would like to express a sincere thank you. I look forward to seeing all of the great things you will accomplish. 
Dr. Elizabeth Gilbert and Dr. Sulaiman Matarneh, thank you for all the help you gave me with my enzyme activity. You gave me a tremendous amount of help setting up the assays and answering all of my questions along the way.

To my friends and coworkers in the Persia lab, I would like to express a deep thank you for all of your help. I would not have been able to do it without your hard work, advice, and friendship. You have all made a positive impact on my life and I am incredibly grateful to have had the opportunity to work alongside of you.

A thank you to the members of the Dalloul lab who helped with my project. Without your help I would not be where I am today.

A huge thank you to Morgan, who helped to encourage me and believed in me even when I didn't believe in myself. You have spent countless hours listening to my presentations, letting me bounce ideas off you, and calming me down even when I know that you would have rather talked about something else. You have made a huge impact and I am truly grateful for all that you have done.

A sincere thank you to my family who has always encouraged me in everything I have done. You have shaped me into the man I am today, and without your support throughout my life I would not be who I am today. You have provided me with endless opportunities and I cannot thank you enough.

Finally, thank you to Dr. Sally Johnson and Dr. David Gerrard for providing me the opportunity to enter into a Master's program in the Department of Animal and Poultry Sciences. 
Table of Contents

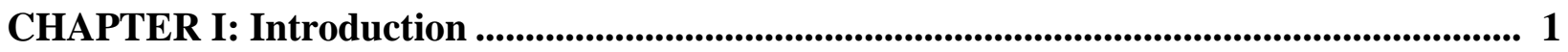

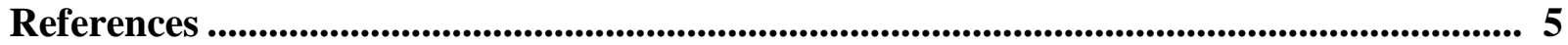

CHAPTER II: Literature Review ........................................................................................................... 7

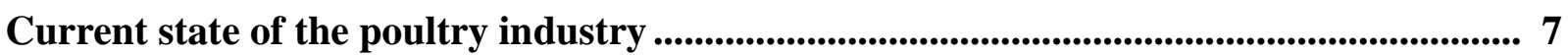

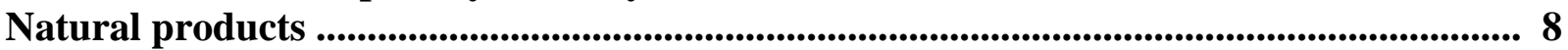

Impact of natural products on growth and performance ........................................................11

Impact of natural products on poultry digestibility ....................................................17

Effect of PFAs on digestive enzyme activity .......................................................................19

Effect of PFAs on nutrient transporter expression ..................................................................23

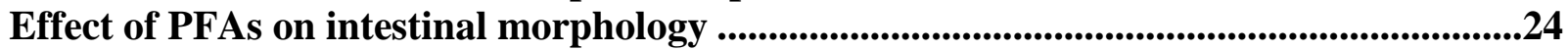

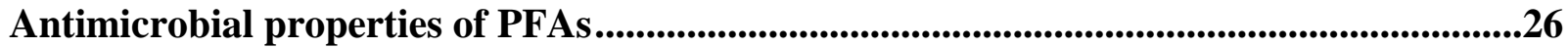

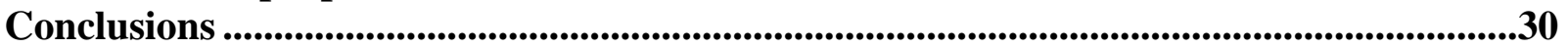

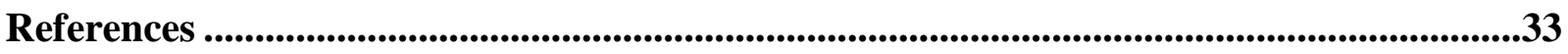

CHAPTER III: Effect of a phytogenic feed additive on turkey poult growth performance and digestibility, digestive enzyme activity, and nutrient transporter mRNA expression ...38

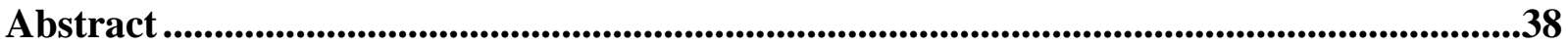

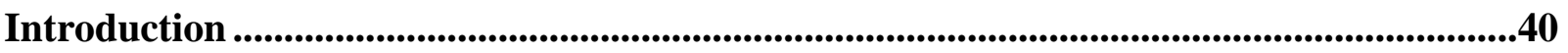

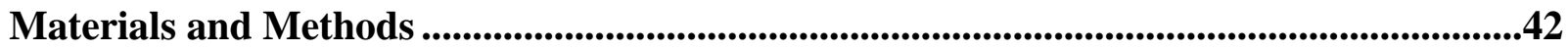

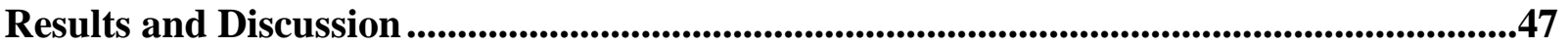

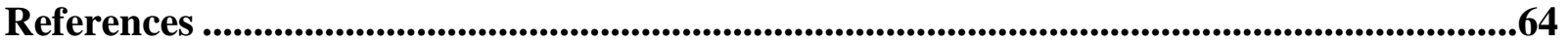

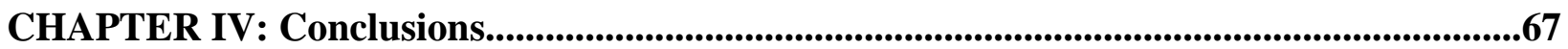

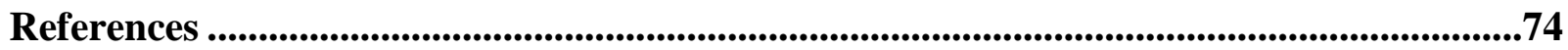


List of Figures and Tables

Figure 1.1. The products of processing various herbs and spices along with their major components. In addition to the major components, several hundred minor components are also present which may help to influence performance by increasing body weight gain and feed efficiency

Table 1.1: Summary of the literature presented in this review on the ability of PFAs to influence body weight gain (BWG), feed conversion ratio (FCR), and mortality in turkeys and broiler chickens.

Table 3.1. Composition of the positive control (PC) and negative control (NC) diets of phase I fed from day-of-hatch until 28 days of age, and phase II fed from 28 days of age until 42 days of age.

Table 3.2. Genes measured using qPCR as well as their full name, function, forward, and reverse primers.

Table 3.3. Initial body weight (IBW), and body weight gain (BWG) of male turkeys raised on clean pine shavings and fed a protein and $\mathrm{AA}$ sufficient $\mathrm{PC}$, protein and $\mathrm{AA}$ deficient NC, or a protein and AA deficient diet supplemented with a phytogenic feed additive.

Table 3.4. Feed efficiency (FE) and cumulative mortality of male turkeys raised on clean pine shavings and fed either a protein and $\mathrm{AA}$ sufficient $\mathrm{PC}$, protein and $\mathrm{AA}$ deficient $\mathrm{NC}$, or protein and $\mathrm{AA}$ deficient diet supplemented with a phytogenic feed additive.

Table 3.5. AMEn and ileal crude protein digestibility (CPD) of male turkeys raised on clean pine shavings and fed either a protein and $\mathrm{AA}$ sufficient $\mathrm{PC}$, a protein and $\mathrm{AA}$ deficient NC, or a protein and AA deficient diet supplemented with a PFA

Table 3.6: Digestible crude protein intake of male turkeys raised on clean pine shavings and fed wither a protein and $\mathrm{AA}$ sufficient $\mathrm{PC}$, a protein and $\mathrm{AA}$ deficient $\mathrm{NC}$, or a protein and AA deficient diet supplemented with a PFA

Table 3.7. Relative mRNA expression of EAAT 3, PepT1, SGLT 1, and GLUT 5 in the jejunum and ileum brush border of male turkeys raised on clean pine shavings and fed either a protein and AA sufficient PC, a protein and AA deficient NC, or a protein and AA deficient diet supplemented with a PFA

Table 3.8. Relative mRNA expression of trypsin, amylase, and lipase in the pancreas of male turkeys raised on clean pine shavings and fed either a protein and $\mathrm{AA}$ sufficient PC, protein and AA deficient $\mathrm{NC}$, or a protein and AA deficient diet supplemented with a PFA

Table 3.9. Specific activity (U/mg total protein) of leucine aminopeptidase, sucrase, maltase, and alkaline phosphatase in the jejunum and ileum at days 28 and 42 of male turkeys raised on clean pine shavings and fed either a protein and $\mathrm{AA}$ sufficient $\mathrm{PC}$, protein and AA deficient NC, or a protein and AA deficient diet supplemented with a PFA. 


\section{CHAPTER I}

\section{INTRODUCTION}

In recent years the amount of poultry consumed by Americans has increased, placing an increased demand on producers (USDA, 2017). This has been coupled with increased regulation of the use of in-feed antibiotics, resulting in the discontinuation of sub-therapeutic antibiotics which have historically been included to improve health and performance. Since this restriction, many farms have experienced particular difficulty when switching to a program without antibiotics resulting in diminished profits due to the loss of performance (Smith, 2011). Researchers have been searching for antibiotic alternatives to prevent the decrease in performance, and potential increase in morbidity and mortality observed in antibiotic free programs. As improvements in bird performance result in increased revenue, research by producers and scientists has focused on alternatives to antibiotics that improve body weight gain (BWG) and feed efficiency (FE). Of these alternatives, one is a class of compounds known generally as phytogenic feed additives (PFAs), which can be loosely defined as plant-based products that have various beneficial properties when consumed in the proper combinations and concentrations (Windisch et al., 2014). These include products such as herbs, essential oils (EOs), botanicals, and oleoresins (DiazSanchez et al., 2015). There are a wide variety of PFAs of agricultural interest, differing in species and extent of processing. Typically, a given PFA will consist of two or three major components present in concentrations between $20-70 \%$, and dozens of minor components present in much lower concentrations (Bakkali et al., 2008). Interest in PFAs as a poultry feed additive has increased in recent years, and as such so has the number of experiments investigating their efficacy as well as the number of companies involved in their production. Despite the increase in the PFA industry, a mode of action has not yet been determined, as it is likely that the modes of action will 
be unique to specific PFA blends due to differences in chemical composition and activity. Chemical composition can vary greatly depending on the species of plant, harvest time, and extraction method, among others (Brenes and Roura, 2010), and can play a large role in determining the effect of a particular PFA

While research in feeding PFAs to poultry has increased, particularly in recent years, there is still a considerable amount of variation among experiments as to the effectiveness of these products in eliciting positive performance benefits. While some researchers report an improvement in performance, other experiments show no differences when PFAs are included in the diet. However, differences in these experiments such as the composition of the basal diet, hygienic standards, and environmental conditions may play a role in the variability (Brenes and Roura, 2010). Additionally, as previously mentioned the composition of a PFA can largely depend on factors such as the species of plant, harvesting time, geographical location, and level and type of processing, which increases variability among PFAs. Therefore, two experiments investigating the same PFA could yield conflicting results due to variation in harvesting and processing. Historically, many experiments did not typically quantify the amount of a particular PFA that was added to the diet, which may help explain some of the variation in past research. Currently, many researchers include a specified amount of PFA into the diet, making comparisons between experiments clearer.

Increased interest in PFAs along with the variation in literature and lack of an established mode-of-action demonstrate a need for additional research investigating the large variety of products. The majority of current interest is in the effects of combinations of components or EOs, and relatively few studies have investigated the effect of a single compound (Hafeez et al., 2016). The large variety of PFAs, including those manufactured commercially, demonstrates the need for 
more research to determine the appropriate combination and concentration of compounds to obtain the greatest performance response. Additionally, few studies have investigated the effect of PFAs on diets which do not contain adequate amounts of major nutrients such as energy, protein, and amino acids. Much of current research on PFAs utilizes broiler chickens, and relatively few experiments investigate their effect on turkeys (Giannenas et al., 2014). This may be because of the larger chicken market in the United States, or due to the shorter production cycle of the broiler chicken. Regardless, it is possible that PFAs function differently in turkeys than they do in chickens, and as such, more research is necessary to determine their effectiveness and mode-ofaction.

The current experiment was designed to investigate the effect of a commercially available PFA on the performance, nutrient digestibility, and nutrient absorption of turkey poults fed a diet with reduced crude protein and limiting amino acids. The birds fed the PFA were compared to a reduced protein and limiting amino acid negative control, as well as a positive control diet formulated to meet the bird's nutrient requirements to determine if the addition of the PFA to the diet could compensate for the reduced nutrients.

It is hypothesized that the addition of the PFA to the diet will improve performance beyond that of the negative control, which may be similar to or greater than the positive control. It is thought that this may occur due to an increase in nutrient digestibility, whether that be energy or protein, due to an increase in absorption capacity, or more efficient utilization of nutrients. Several experiments have investigated the impact of PFAs on digestibility and have found that their addition to the diet improved protein and fat digestibility (Jamroz et al., 2003; Hernandez et al., 2004; Amad et al., 2011), while others have shown that they have no influence on the digestibility of these nutrients (Mountzouris et al., 2011; Pirgozliev et al., 2015). However, little data are 
available regarding the effect of PFAs on nutrient absorption. Fernandez-Alarcon and coworkers (2017) reported no difference in the expression of peptide transporter 1 (PepT1) in broilers when a PFA was supplemented in the diet. Additionally, there were no differences in several glucose and fructose transporters. Aside from nutrient transporters, published data are not available regarding the effect of PFAs on pancreatic enzyme mRNA expression, which could be a possible reason for the increase in pancreatic enzyme activity reported by Hashemipour and coworkers (2013). Finally, current data regarding how PFAs affect intestinal digestive enzymes is inconsistent, with Jang and coworkers (2007) reporting opposite effects compared to FernandezAlarcon and coworkers (2017) in regard to the effect of PFAs on aminopeptidase, maltase, and alkaline phosphatase activity. Therefore, the data generated in this experiment may help verify previously published results, as well as examine how a PFA impacts digestive physiology in young turkeys. 


\section{References}

Amad, A. A., K. Manner, K. R. Wendler, K. Neumann, and J. Zentek. 2011. Effects of a phytogenic feed additive on growth performance and ileal nutrient digestibility in broiler chickens. Poult. Sci. 90:2811-2816.

Bakkali, F., S. Averbeck, D. Averbeck, and M. Idaomar. 2008. Biological effects of essential oils-A review. Food Chem. Toxicol. 46:446-475.

Brenes, A., and E. Roura. 2010. Essential oils in poultry nutrition: Main effects and modes of action. Anim. Feed Sci. Technol. 158:1-14.

Diaz-Sanchez, S., D. D'Souza, D. Biswas, and I. Hanning. 2015. Botanical alternatives to antibiotics for use in organic poultry production. Poult. Sci. 94:1419-1430.

Fernandez-Alarcon, M. F., N. Trottier, J. P. Steibel, R. Lunedo, D. M. B. Campos, A. M. Santana, J. M. Pizauro, R. L. Furlan, and L. R. Furlan. 2017. Interference of age and supplementation of direct-fed microbial and essential oil in the activity of digestive enzymes and expression of genes related to transport and digestion of carbohydrates and proteins in the small intestine of broilers. Poult. Sci. 96:2920-2930.

Giannenas, I., C. P. Papaneophytou, E. Tsalie, I. Pappas, E. Triantafillou, D. Tontis, and G. A. Kontopidis. 2014. Dietary supplementation of benzoic acid and essential oil compounds affects buffering capacity of the feeds, performance of turkey poults and their antioxidant status, $\mathrm{pH}$ in the digestive tract, intestinal microbiota and morphology. Asian-Aust. J. Anim. Sci. 27:225-236.

Hafeez, A., K. Manner, C. Schieder, and J. Zentek. 2016. Effect of supplementation of phytogenic feed additives (powdered vs. encapsulated) on performance and nutrient digestibility in broiler chickens. Poult. Sci. 95:622-629.

Hashemipour, H., H. Kermanshahi, A. Golian, and T. Veldkamp. 2013. Effect of thymol and carvacrol feed supplementation on performance, antioxidant enzyme activities, fatty acid composition, digestive enzyme activities, and immune response in broiler chickens. Poult. Sci. 92:2059-2069.

Jang, I. S., Y. H. Ko, S. Y. Kang, and C. Y. Lee. 2007. Effect of a commercial essential oil on growth performance, digestive enzyme activity and intestinal microflora population in broiler chickens. Anim. Feed Sci. Technol. 134:304-315.

Mountzouris, K. C., V. Paraskevas, P. Tsirtsikos, I. Palamidi, T. Steiner, G. Schatzmayr, and K. Fegeros. 2011. Assessment of a phytogenic feed additive effect on broiler growth performance, nutrient digestibility and caecal microflora composition. Anim. Feed Sci. Technol. 168:223-231.

Pirgozliev, V., D. Bravo, M. W. Mirza, and S. P. Rose. 2015. Growth performance and endogenous losses of broilers fed wheat-based diets with and without essential oils and xylanase supplementation. Poult. Sci. 94:1227-1232.

Smith, J.A. 2011. Experiences with drug-free broiler production. Poult. Sci. 90:2670-2678. 
USDA. 2017. Livestock and poultry: world markets and trade. October 2017. United States Department of Agriculture-Foreign Agricultural Service, Washington, DC. https://apps.fas.usda.gov/psdonline/circulars/livestock_poultry.pdf

Windisch, W., K. Schedle, C. Plitzner, and A. Kroismayr. 2008. Use of phytogenic products as feed additives for swine and poultry. J. Anim. Sci. 86:E140-E148. 


\section{CHAPTER II}

\section{REVIEW OF LITERATURE}

\section{Current state of the poultry industry}

In the United States, the poultry industry consists of several facets with the majority of the industry comprising broilers, layers, and turkeys. The per capita consumption of poultry meat was 214.6 pounds in 2016, compared to 208.9 pounds in 2010 (National Chicken Council, 2017). Until recently, antibiotics were fed at sub-therapeutic levels in increase BWG, improve FCR, and reduce the incidence of disease (Gaucher et al., 2015). The exact mechanisms through which antibiotics function is not fully understood, though several mechanisms have been proposed such as the inhibition of sub-clinical infections, the reduction of growth-depressing microbial metabolites, reduction of the amount of nutrients used by intestinal microbes, and increase in nutrient uptake due to reduced intestinal wall thickness (Applegate et al., 2010). There are also improvements in animal health and welfare when antibiotics are included at sub-therapeutic concentrations as Gaucher and coworkers (2015) saw a significant reduction in clinical necrotic enteritis outbreaks and subclinical enteritis cases in a conventional program compared to a drug-free program. Some companies report particular difficulty when switching to an antibiotic free program, with increased FCR, decreased BWG, and significant increases in disease (Smith, 2011). There are currently many feed additives on the market designed to increase BW, decrease FCR, or control infection in poultry, one of which being natural products, or PFAs. 


\section{Natural products}

Loosely defined, PFAs are plant-derived products from herbs and spices used in animal feeding which may improve growth performance, make feed more palatable, and possess antimicrobial activity (Windisch et al., 2014). These compounds can be further differentiated into four classes including herbs, EOs, botanicals, and oleoresins (Diaz-Sanchez et al., 2015). Herbs and botanicals tend to be entire plants or parts of plants, while EOs and oleoresins are further processed through steam distillation or extractions using non-aqueous solvents (Diaz-Sanchez et al., 2015; Greathead, 2003). Essential oils in particular are mixtures of secondary plant metabolites of low-boiling phenylpropenes and terpenes (Brenes and Roura, 2010).

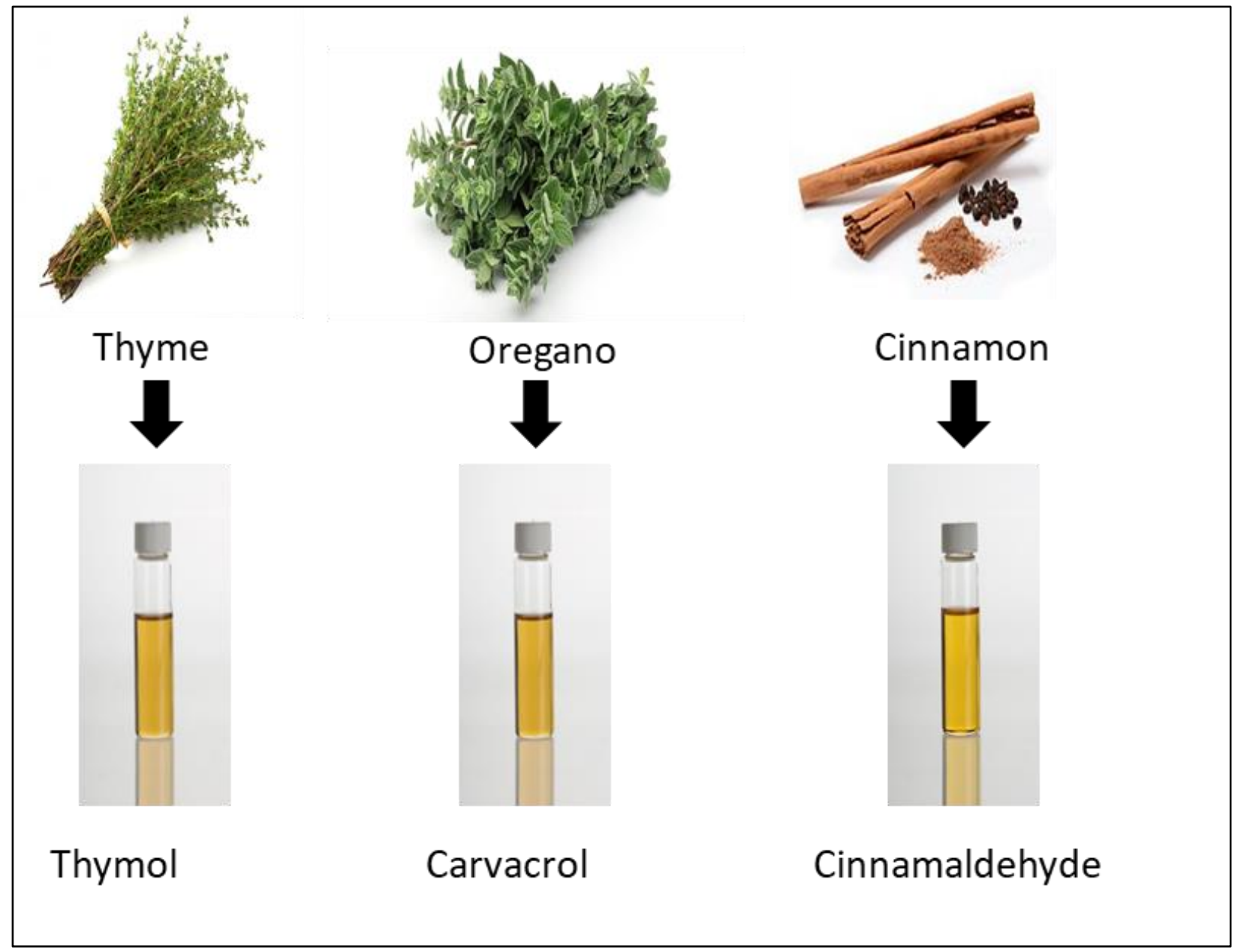


Figure 2.1: The products of processing various herbs and spices along with their major components. In addition to the major components, several hundred minor components are also present which may help to influence performance by increasing body weight gain and feed efficiency.

These compounds are categorized as "generally recognized as safe" by the United States Food and Drug Administration, and the bioactive compounds tend to be metabolized quickly making accumulation in the body unlikely (Gopi et al., 2013; Brenes and Roura, 2010). While current research has produced varying results, PFAs have been shown to produce a variety of positive effects when included in poultry diets. As the physiological properties of PFAs depends on their chemical composition, the variability in results may be related to the plant's origin, harvesting time, state of maturity, and the extraction method used to develop the PFA (Brenes and Roura, 2010). Additionally, in the past researchers did not typically characterize and quantify the PFAs being fed, which may have contributed to the variation in results. In contrast, most current research characterizes the feed additives, leading to more consistent results. Approximately 3,000 EOs are known, with 300 of those being important for the pharmaceutical, agronomic, food, sanitary, cosmetic, and perfume industries. These oils can contain between 20 and 60 components at varying concentrations, with two or three major components present in concentrations between 20 and 70\% (Bakkali et al., 2008). Two common EOs used in poultry feeds are oils from oregano and thyme. Distilling oregano results in the major constituents of oxygenated monoterpenes, including carvacrol, thymol, $\beta$-fenchyl alcohol, and $\delta$-terpineol (Teixeira et al., 2013). The extraction of thyme gives rise to the major components thymol and p-cymene present at concentrations between $30 \%$ and 50\%, and $8 \%$ and 30\% respectively (Boruga et al., 2014; Grigore et al., 2010). 
One well known trait of EOs is their ability to kill pathogenic bacteria. As many as 19 phytogenic compounds have been shown to exhibit bactericidal effects (Applegate et al., 2010). Oregano EOs have been shown to have in vitro antimicrobial activity, measured by inhibition zones (Soković et al., 2010; Si et al., 2006). Carvacrol and thymol, the major components of this EO, had strong antimicrobial activity against $E$. coli and $S$. typhimurium when present at $1 \mu \mathrm{g} / \mathrm{mL}$, and the inhibition zone was approximately $73 \%$ larger compared to streptomycin (Sokovic et al., 2010). However, the antimicrobial activity is dependent on not only the chemical compound, but also the species of bacteria as compounds such as limonene are much less effective against $E$. coli and S. typhimurium compared to carvacrol and thymol. This in vitro antimicrobial activity has prompted several researchers to investigate if these compounds have in vivo antimicrobial effects in broiler chickens (Cross et al., 2007; Betancourt et al., 2014; Peng et al., 2016) and turkeys (Bampidis et al., 2005).

With growing pressure to shift away from synthetic drugs, interest in alternative feed additives for poultry has increased. Concern for the generation of antibiotic resistance of human pathogens through the inclusion of antibiotics in poultry diets has caused new legislation regulating the addition of antibiotics to feed (Food and Drug Administration, 2015). Additionally, the antibiotic-free label provides restaurants and retailers with a way to differentiate their poultry products to consumers. With the Veterinary Feed Directive in full effect as of January 1, 2017, producers are no longer able to feed antibiotics at sub-therapeutic levels to enhance growth and prevent incidence of disease. These antibiotics were originally fed to poultry to improve BWG and FCR and reduce the incidence of disease, increasing profits to the farmer. Because of this, PFAs are being investigated as a preventative feed additive and an alternative to feeding antibiotics, as these have several positive benefits to the bird. If the antimicrobial activity of PFAs can be utilized 
to modulate the intestinal microbiome and prevent poultry from becoming diseased, antibiotics may not be needed to improve health and performance. Interest largely rises from the effects of combinations of several PFAs, with relatively few studies investigating the impact of individual compounds (Hafeez et al., 2016).

\section{Impact of natural products on growth and performance}

Several experiments have demonstrated positive results when PFAs are fed to turkeys. Giannenas and coworkers (2014) found that turkeys supplemented with an EO mixture characterized by thymol, eugenol, and piperine at $30 \mathrm{mg} / \mathrm{kg}$ had 7\% higher BW and 7\% improved FCR compared to turkeys fed thymol alone at $30 \mathrm{mg} / \mathrm{kg}$, or a control diet through 56 days. This effect was also observed at 28 days of age, with the mixture of EOs having $6 \%$ higher BW and $3 \%$ improved FCR than both the thymol supplemented turkeys and the control. This comparison illustrates the effect that minor compounds play on the ability of a PFA to positively influence poult performance. Although thymol is one of the major components present in the mixture of EOs, the birds fed the mixture were able to outperform the thymol only supplemented birds suggesting that the minor components could be having their own effect on performance, or are able to enhance the effect of the major components. Bampidis and coworkers (2005) showed that the performance of early maturing turkeys can be improved when supplemented with dried oregano leaves. The birds were supplemented with dried oregano leaves at either 45, 90, and 135 $\mathrm{mg} / \mathrm{kg}$ through 84 days of age. Although there were no differences in BW, feed efficiency (FE) was significantly improved between 43 to 84 days of age, and 1 to 84 days of age. Surprisingly, feed intake (FI) was significantly decreased with increasing concentration of oregano leaves in the diet, and the authors suggested that there may be an odor or reduction in palatability associated with the leaves. While these experiments suggest positive effects associated with feeding PFAs to 
turkeys, they are limited in number and scope, with the majority of research being conducted in broiler chickens.

A commercial mixture of carvacrol, cinnamaldehyde, and capsicum oleoresin at 5\%, 3\%, and 2\% (XT; XTRACT 6930, Pancosma S.A., Geneva, Switzerland) have been shown to improve broiler BWG by $15 \%$ and tended $(P=0.06)$ to improve FCR by $10 \%$ when fed a standard cornsoy diet (Bravo et al., 2014). Another experiment using the same feed additive in broilers showed a significant increase in BW, FE, and FI through 21 days of age (Pirgozliev et al., 2015). While EOs and oleoresins are typically composed of many active chemicals, some research has been conducted investigating the effect of the major compounds present in EOs. A 1:1 mixture of carvacrol and thymol was shown to elicit positive growth benefits, increasing BWG by $3 \%$ and FCR by $5 \%$ when fed to unchallenged broilers (Hashemipour et al., 2013). Oregano EO alone, included at $300 \mathrm{mg} / \mathrm{kg}$ and $600 \mathrm{mg} / \mathrm{kg}$ improved broiler BWG at 42 days of age (Peng et al., 2016). Broilers fed the oregano EO at $300 \mathrm{mg} / \mathrm{kg}$ or $600 \mathrm{mg} / \mathrm{kg}$ had the highest BW at 42 days of age, though at 21 days of age only the birds fed the EO at $600 \mathrm{mg} / \mathrm{kg}$ had significantly higher BW. Surprisingly, FCR was only significantly different through 21 days of age, with the broilers fed the highest inclusion of oregano EO having the lowest FCR. Murugesan and coworkers (2015) noted a significant increase in BW at 39 days of age when broilers were fed a commercial PFA (Digestarom ${ }^{\circledR}$, Biomin Holding GmbH, Austria). They also noted a 7\% reduction in FCR compared to both the control diet and similar to the antibiotic diet throughout the 39 day growout period. During the grower period from 22 days of age until 39 days of age, the PFA reduced FCR by $7 \%$ compared to the antibiotic and $10 \%$ compared to the control.

There is some dispute over the effects of PFAs on bird performance, as some experiments have shown no significant improvement in performance when plant extracts are included in the 
diet (Hernandez et al., 2004). However, performance data presented in this study have low replication $(n=3)$, and thus the experiment may not have had enough statistical power to detect significant differences. Additionally, the experiment was started when the birds were 7 days of age and the positive effects of PFAs may be most critical at a young age when the digestive system is still developing. Additionally, some of this variation may also arise from the vast number of PFAs being studied, as well as the concentrations they are being added into the diet. Several experiments have shown linear increases in performance with increasing PFA concentration. For example, a PFA consisting of EOs with thymol and anethole as the major components improved broiler FCR linearly with increasing PFA concentrations of 150,750 , and 1,500 mg/kg in the diet (Amad et al., 2011). Birds fed the PFA at $1,500 \mathrm{mg} / \mathrm{kg}$ had $7 \%$ lower FCR than the control birds. Similarly, a PFA consisting of carvacrol, anethole, and limonene as the major components improved BWG and FCR of broilers in a similar manner, but at lower concentrations of 80,125 , and $250 \mathrm{mg} / \mathrm{kg}$ (Mountzouris et al., 2011). Although a linear trend was not observed, birds fed the highest concentration of a PFA consisting of a blend of EOs from basil, caraway, laurel, lemon, oregano, sage, tea, and thyme had improved FE, although BWG did not follow a similar trend (Khattak et al., 2014). The improvements seen at lower concentrations may be due to differences in the potency of the chemicals making up the PFA.

Interestingly, form of the PFAs included in the diet has also been shown to play a role in the performance benefits. Encapsulation is an additional step during processing in which a functional barrier is added between the core and wall of the feed additive to prevent chemical and physical reactions (Bakry et al., 2015). Encapsulation has been applied in both the food and pharmaceutical industries to control the release time of the active ingredient (Fang and Bhandari, 2010). Additionally, encapsulation has been shown to reduce oxidation and undesirable odors and 
taste in cheese with microencapsulated fish oil (Ye et al., 2009). Reduced oxidation will also allow the feed additives to be stored longer and in more variable conditions. A powdered PFA consisting of menthol and anethole and an encapsulated PFA consisting of carvacrol, thymol, and limonene were included at $150 \mathrm{mg} / \mathrm{kg}$ and $100 \mathrm{mg} / \mathrm{kg}$ respectively and compared to a control diet in broiler chickens, with the encapsulated PFA having $2 \%$ greater BWG compared to the control and 2\% lower FCR compared to both the control and powdered PFA at 42 days of age (Hafeez et al., 2016). The diets were pelleted with the temperature in the conditioner adjusted to $50^{\circ} \mathrm{C}$. Thus, this difference may be largely due to the increased protection associated with the encapsulation, which protects the active ingredients from being degraded by the high temperatures, although some of the difference could arise from the difference in chemical make-up of the PFA. A summary of some of the results of previous experiments when PFAs were fed to turkeys and broilers is presented in Table 2.1. 
Table 2.1: Summary of the literature presented in this review on the ability of PFAs to influence body weight gain (BWG), feed conversion ratio (FCR), and mortality in turkeys and broiler chickens.

\begin{tabular}{|c|c|c|c|c|c|c|}
\hline Species & Strain & PFA (concentration) & BWG & FCR & Mortality & Reference \\
\hline Turkey & Nicholas 300 & $\begin{array}{c}\text { Thymol, eugenol, } \\
\text { piperine } \\
(30 \mathrm{mg} / \mathrm{kg})\end{array}$ & $\uparrow$ & $\downarrow$ & $\mathrm{NA}^{1}$ & $\begin{array}{c}\text { Giannenas et al., } \\
2014\end{array}$ \\
\hline Turkey & $\begin{array}{l}\text { Nicholas } \\
\text { White }\end{array}$ & $\begin{array}{l}\text { Dried oregano leaves } \\
\quad(45-135 \mathrm{mg} / \mathrm{kg})\end{array}$ & $\mathrm{ND}^{2}$ & $\downarrow$ & ND & $\begin{array}{l}\text { Bampidis et al., } \\
2005\end{array}$ \\
\hline Broiler & Ross 308 & $\begin{array}{l}\text { Carvacrol, } \\
\text { cinnamaldehyde, and } \\
\text { capsicum } \\
(100 \mathrm{~g} / \mathrm{t})\end{array}$ & $\uparrow$ & $\downarrow^{3}$ & ND & Bravo et al., 2014 \\
\hline Broiler & Ross 308 & $\begin{array}{l}\text { Carvacrol, } \\
\text { cinnamaldehyde, and } \\
\text { capsicum } \\
(100 \mathrm{~g} / \mathrm{t})\end{array}$ & $\uparrow$ & $\downarrow$ & ND & $\begin{array}{l}\text { Pirgozliev et al., } \\
2015\end{array}$ \\
\hline Broiler & Ross 308 & $\begin{array}{c}\text { Thymol and carvacrol } \\
(60-200 \mathrm{mg} / \mathrm{kg})\end{array}$ & $\uparrow$ & $\downarrow$ & NA & $\begin{array}{l}\text { Hashemipour et } \\
\text { al., } 2013\end{array}$ \\
\hline Broiler & Arbor Acres & $\begin{array}{c}\text { Carvacrol and thymol } \\
(600 \mathrm{mg} / \mathrm{kg})\end{array}$ & $\uparrow$ & ND & ND & Peng et al., 2016 \\
\hline Broiler & Ross & $\begin{array}{c}\text { Oregano, cinnamon, and } \\
\text { pepper } \\
(200 \mathrm{ppm})\end{array}$ & ND & ND & $\downarrow$ & $\begin{array}{c}\text { Hernandez et al., } \\
2004\end{array}$ \\
\hline Broiler & Cobb 500 & $\begin{array}{l}\text { Thymol and anethole } \\
(150-1,500 \mathrm{mg} / \mathrm{kg})\end{array}$ & ND & $\downarrow$ & ND & Amad et al., 2011 \\
\hline Broiler & Cobb 500 & $\begin{array}{l}\text { Carvacrol, thymol, and } \\
\text { limonene } \\
(100 \mathrm{mg} / \mathrm{kg})\end{array}$ & $\uparrow$ & $\downarrow^{*}$ & ND & Hafeez et al., 2016 \\
\hline Broiler & Ross 308 & $\begin{array}{l}\text { Basil, caraway, laurel, } \\
\text { lemon, oregano, sage, } \\
\text { tea, and thyme } \\
(15-60 \mathrm{mg} / \mathrm{kg})\end{array}$ & $\uparrow$ & $\downarrow$ & ND & $\begin{array}{c}\text { Khattak et al., } \\
2014\end{array}$ \\
\hline Broiler & Cobb & $\begin{array}{c}\text { Oregano, anise, and } \\
\text { citrus } \\
(80-250 \mathrm{mg} / \mathrm{kg})\end{array}$ & $\uparrow$ & $\downarrow$ & ND & $\begin{array}{c}\text { Mountzouris et al., } \\
2011\end{array}$ \\
\hline Broiler & Vencobb 400 & $\begin{array}{l}\text { Combination of } 30 \text { EOs } \\
(150 \mathrm{mg} / \mathrm{kg})\end{array}$ & $\uparrow$ & $\downarrow$ & ND & $\begin{array}{l}\text { Murugesan et al., } \\
2015\end{array}$ \\
\hline
\end{tabular}

${ }^{1}$ Data were not available.

${ }^{2}$ No difference.

${ }^{3}$ Data were not statistically significant, but there was a trend $(P \leq 0.10)$.

* Data were only significant during finisher phase and no effect was seen for overall FCR. 
PFAs have been evaluated primarily in meat-type birds, although there is some evidence that they improve laying hen performance. Unlike broilers, laying hens have a much longer production cycle. Garlic powder was found to have non-significant improvements on FCR when included at 3\% in a laying hen diet (Olobatoke and Mulugeta, 2011). However, when included at $5 \%$ there was a significant decrease in egg production and an increase in FCR. This may be due to feed refusal by the hens, or potentially that the garlic powder caused an adverse reaction at higher concentrations. Although FI was not significantly different among treatments, there was a numerical decrease in FI with increasing concentration of garlic powder in the diet. Interestingly, there was a significant increase in egg quality when garlic powder was included in the hens' diet. Haugh unit, a measure of protein quality, was significantly improved when hens were fed 3\% garlic powder compared to the control, although there were no differences in the yolk and shell weight. Melon concentrate has also been shown to increase egg weight, shell weight, and yolk weight when included in the diet at $46 \mathrm{mg} / \mathrm{kg}$ (Carillon et al., 2016). However, no differences in Haugh unit were noted. Although the data are rather limited compared to broilers, there is evidence suggesting that PFAs have a positive effect on laying hen performance.

While several studies have shown that PFAs can improve performance in broiler chickens, the variability in the literature demonstrates a need for more experiments evaluating the effects of various PFAs. Additionally, there is relatively little research available demonstrating the efficacy of these products in turkey diets. It also appears that these products may have varying effects based on the particular level of processing and growing situation, requiring more research on these conditions. 


\section{Impact of PFAs on poultry digestibility}

One proposed mechanism for the improvement in performance seen when poultry are fed PFAs is an increase in nutrient digestibility. By increasing the digestibility of feed, the bird can obtain more nutrients from the diet allowing for more resources allocated to performance requirements.

Researchers have investigated PFAs for their impact on crude protein $(\mathbf{C P})$ digestibility in poultry. Amad and coworkers (2011) reported an increase in apparent ileal digestibility compared to the control of $\mathrm{CP}$ at days 21, 35, and 42 when broilers were fed an EO containing thymol and anethole at either 150,750 , or $1,500 \mathrm{mg} / \mathrm{kg}$. The diets were formulated to be isonitrogenous, and contained $24.6 \% \mathrm{CP}$ during the starter phase and $23.7 \% \mathrm{CP}$ during the finisher phase. There was a linear improvement of $\mathrm{CP}$ digestibility with increasing supplementation of the EO, with the greatest response observed at $1,500 \mathrm{mg} / \mathrm{kg}$. Another experiment compared broilers fed a control diet composed of corn, soy, and wheat to a diet containing an antibiotic (Avilamycin) and two PFAs; a 200 ppm EO extract from oregano, cinnamon, and pepper, and a 5,000 ppm extract (LE) from sage, thyme, and rosemary (Hernandez et al., 2004). The authors found that the EO extract improved whole-tract $\mathrm{CP}$ digestibility in the finisher phase, though no improvements were seen in whole-tract or ileal CP digestibility in the starter phase. The data from Hernandez and coworkers (2004) may provide evidence that certain PFAs are most effective at a particular part in life, or at a certain point in development in the gastrointestinal tract (GIT). In an experiment investigating the effects of a commercially available PFA on broilers (XT; XTRACT 6930, Pancosma S.A., Geneva, Switzerland) consisting of carvacrol, cinnamaldehyde, and capsaicin, ileal CP digestibility was improved by $3 \%$ at 21 days of age compared to a wheat, barley, and soybean control diet containing 21.5\% CP (Jamroz et al., 2003). Similarly, turmeric meal improved broiler 
ileal CP digestibility by $3 \%$ compared to a wheat-soy control diet containing $22 \% \mathrm{CP}$ when included at $10 \mathrm{~g} / \mathrm{kg}$ (Olukosi and Dono, 2014). An encapsulated PFA consisting of carvacrol, thymol, and limonene included at $100 \mathrm{mg} / \mathrm{kg}$ was found to improve CP digestibility in 21 day old broilers compared to a corn-soy control diet with $20 \% \mathrm{CP}$, and powdered PFA consisting of menthol and anethole included at $150 \mathrm{mg} / \mathrm{kg}$ (Hafeez et al., 2016). However, the powdered and encapsulated PFAs were included at different concentrations and had different chemical compositions making comparisons between the two diets difficult. The individual PFAs can be compared to the control diet, and these data indicate that the encapsulated PFA may improve CP digestibility compared to a standard corn-soy ration. Based on the results of these studies, there is evidence that protein digestibility is improved when broilers are supplemented with PFAs. However, research regarding the impact of PFAs on turkey $\mathrm{CP}$ digestibility is limited, demonstrating a need for additional experiments to determine if these products function similarly in turkeys as they do in broilers.

Energy digestibility has also been shown to be impacted when poultry are fed PFAs. Amad and coworkers (2011) demonstrated that broiler crude fat digestibility linearly improved at 21, 35, and 42 days of age with increasing supplementation from $150 \mathrm{mg} / \mathrm{kg}$ to $1,500 \mathrm{mg} / \mathrm{kg}$ of an EO containing thymol and anethole. Fat digestibility was $4 \%$ higher in broilers supplemented with $1,500 \mathrm{mg} / \mathrm{kg}$ of the EO compared to the control on days 21 and 35, and 3\% higher on day 42. Similar findings were reported when broilers were fed the EO extract of oregano, cinnamon, and pepper or LE from sage, thyme, and rosemary, with whole-tract crude fat digestibility being $2 \%$ higher in the EO mixture, or 5\% higher for LE compared to the wheat-soy control in the starter phase (Hernandez et al., 2004). However, this effect was not observed in the finisher phase. Ileal starch digestibility was also significantly higher by $1 \%$ in the EO mixture and LE treatments 
compared to the control treatment in the starter phase, but again this was not observed in the finisher phase. Turmeric meal was shown to improve nitrogen corrected apparent metabolizable energy (AMEn) by 4\% compared to a wheat-soy comtrol diet when included at $10 \mathrm{~g} / \mathrm{kg}$ (Olukosi and Dono, 2014). In a separate experiment by the same authors garlic meal provided a similar effect as turmeric meal, improving AMEn by $6 \%$ compared to the same control diet when included at $10 \mathrm{~g} / \mathrm{kg}$. Jamroz and coworkers (2003) showed that XT can increase crude fat digestibility in 21 day old broilers by $14 \%$ compared to a wheat, barley, and soybean control diet when included at $300 \mathrm{ppm}$. However, there were no differences seen in apparent ileal energy digestibility nor were there any differences observed in crude fat or energy digestibility after 32 days of feeding. These data are similar to those seen with this feed additive on protein digestibility, with XT improving crude protein digestibility at 21 days of age but not 32 days of age.

Previous research provides evidence that PFAs as a class can improve nutrient digestibility in broilers, which may contribute to the improvement in performance when PFAs are supplemented. However, the large variety of PFAs, as well as variation in their effects on digestibility warrants more research. Additionally, there is little data available as to how these compounds influence digestibility in turkeys, which may be markedly different than that of broilers.

\section{Effect of PFAs on digestive enzyme activity}

There are several proposed modes of action for the improvement in digestibility observed when poultry are fed PFAs, one of which is an increase in digestive enzyme activity. Digestive enzymes in the GIT catalyze the breakdown of larger macronutrients into smaller molecules that the animal can more readily absorb. One proposed mechanism for the positive effects of PFAs on poultry production is the stimulation of endogenous enzymes to increase the digestion and 
absorption of nutrients from the diet (Williams and Losa, 2001). When nutrients reach the duodenum of the small intestine they encounter enzymes secreted by the pancreas and brush border membrane that begin to catalyze their breakdown. As the digesta continues into the jejunum and ileum, brush border enzymes further breakdown these partially digested nutrients into monomers or dimers that the animal is able to readily absorb. By increasing the activity of these enzymes, nutrients can be broken down more efficiently and digestibility is improved.

Phytogenic feed additives have been shown to improve the activity of several pancreatic enzymes. Three commonly measured enzymes are trypsin, a serine protease which hydrolyzes proteins from the C-terminus of lysine and arginine, amylase which hydrolyzes starch into simple sugars, and lipase which breaks down lipids into glycerides and fatty acids. Jang and coworkers (2007) observed an increase in total and specific trypsin activity and total amylase activity in the pancreas of broilers fed a commercial PFA. Broilers were fed a PFA with thymol, eugenol, and piperine as the leading components at $25 \mathrm{mg} / \mathrm{kg}$ and $50 \mathrm{mg} / \mathrm{kg}$, a diet with $10 \mathrm{mg} / \mathrm{kg}$ inclusion of Colistin, an antibiotic included at $10 \mathrm{mg} / \mathrm{kg}$, or a control diet and the activity of several pancreatic enzymes were measured at 35 days of age. A $50 \%$ increase in total trypsin activity and a $36 \%$ increase in specific trypsin activity was observed by the birds fed the $50 \mathrm{mg} / \mathrm{kg}$ EO diet compared to the control. Total amylase activity was increased by $38 \%$ in birds fed the $50 \mathrm{mg} / \mathrm{kg}$ EO diet compared to the control, and although there was not statistical significance, specific amylase activity was increased in EO fed birds compared to the control. Enzyme activity was also improved in birds fed the $25 \mathrm{mg} / \mathrm{kg}$ EO diet, though not to the extent of the birds fed the higher concentration of EO. The antibiotic in the feed did not have an impact on digestive enzyme activity compared to the control, and was lower than that of the PFA fed birds. Another experiment investigating the same feed additive fed to broilers at $100 \mathrm{ppm}$ found that at 21 days of age the broilers fed the PFA 
had a 30\% increase in amylase activity in the intestine (Lee et al., 2003). However, they did not note any differences in trypsin, lipase, or chymotrypsin at any age and did not note improvements in amylase activity at 40 days of age. Some of the difference in enzyme activity between these two studies may arise from the bird's age, as well as the concentration the EO was included in the diet. Hashemipour and coworkers (2013) performed a similar experiment investigating the effect of a 1:1 ratio of thymol and carvacrol on pancreatic enzyme activity. Broilers were given a control diet or supplemented with 60,100 , or $200 \mathrm{mg} / \mathrm{kg}$ of the feed additive and pancreatic enzyme activity was determined on days 24 and 42 . However, the authors measured the enzyme activity of pancreatic enzymes in the lumen of the intestine as well as the pancreas. Since the enzymes secreted by the pancreas encounter cofactors and other molecules that activate them and increase their activity, measurements made in the lumen of the duodenum are more indicative of actual digestive enzyme activity during digestion. In the intestine of birds fed the $200 \mathrm{mg} / \mathrm{kg}$ diet, trypsin activity was improved by $18 \%$, lipase activity was improved by $40 \%$, and protease activity was improved by $25 \%$ compared to the control. Additionally, a linear response was seen for trypsin and lipase, with activity linearly increasing with increasing concentration. A quadratic response was seen for peptidases, most likely arising from the saturation of enzymes with substrate such that their activity is already maximized at the higher inclusion rate of PFA. Similar trends were seen in the pancreas, and trypsin, lipase, and protease activity was improved in birds supplemented with the PFA. In both the intestine and pancreas there was no difference in the activity of amylase. Interestingly, this effect was only seen at 24 days of age, and there were no differences in the activity of any enzyme measured in either the intestine or pancreas at 42 days of age. These results agree with those published by Jang and coworkers (2007) and Lee and coworkers (2003), with the increase in enzyme activity occurring at a younger age. 
Several researchers have investigated the effect of PFAs on brush border membrane enzymes. Jang and coworkers (2004) fed broilers a commercial PFA consisting of thymol, eugenol, and piperine (CRINA®, Akzo Nobel, Crina S.A., Switzerland) at $25 \mathrm{ppm}$, lactic acid at $0.1 \%$, or a combination of CRINA ${ }^{\circledR}$ and lactic acid, and measured the activity of maltase, sucrase, and leucine aminopeptidase (LAP) in the proximal intestine at 35 days of age. There were no differences seen across treatments for sucrase and LAP, although maltase activity was significantly increased when broilers were fed a combination of CRINA® and lactic acid. This difference was not seen when broilers were fed either CRINA® or lactic acid alone, indicating a possible synergistic effect. In another experiment, broilers were fed CRINA® at either $25 \mathrm{mg} / \mathrm{kg}$ or 50 $\mathrm{mg} / \mathrm{kg}$ and the same brush border membrane enzymes were measured (Jang et al., 2007). Similar to the previous experiment there were no differences in sucrase or LAP activity. Total maltase activity was significantly increased with supplementation of CRINA ${ }^{\circledR}$ at $50 \mathrm{mg} / \mathrm{kg}$, but there were no differences at $25 \mathrm{mg} / \mathrm{kg}$. This suggests that CRINA® has a greater effect with an increased concentration, though this may not hold true at higher inclusion. Contrary to the previous experiments, Fernandez-Alarcon and coworkers (2017) showed an increase in aminopeptidase N when broilers were supplemented with Activo ${ }^{\circledR}$ (GRASP Ltda., Curitiba-PR, Brazil), an EO consisting of carvacrol, cinnamaldehyde, cineol, and pepper extract at $125 \mathrm{mg} / \mathrm{kg}$. This difference could be due to differences in the chemical composition of the PFA, suggesting that the composition could influence whether protein or energy yielding enzymes are activated.

These experiments provide evidence that increases in digestive enzyme activity may be contributing to the improvement in digestibility seen when poultry are fed PFAs. It seems that the composition of the feed additive plays a large role in determining its effects on enzyme activity. 
These differences may be the reason for activation of pancreatic versus brush border enzymes, and even the activation of proteases versus energy yielding enzymes.

\section{Effect of PFAs on nutrient transporter expression}

Another proposed mode of action for the improvement in digestibility generated when poultry are fed PFAs is an increase in the activity or number of several nutrient transporters. Nutrient transporters are transmembrane proteins in the cell that are responsible for transporting nutrients from the lumen of the intestine into the enterocyte. These transporters can include single amino acid transporters such as the glutamate transporter, excitatory amino acid transporter 3 (EAAT 3), monosaccharide transporters such as sodium glucose linked transporter 1 (SGLT 1) and fructose transporter 5 (GLUT 5), or peptide transporter 1 (PepT1) which transports di- and tri- peptides. One potential mechanism for an increase in transporter activity or number is an increase in the mRNA expression of those transporters. Some work has been done investigating PFAs for their effect on increasing the mRNA expression of these transporters, though it is limited. Fernandez-Alarcon and coworkers (2017) investigated the effects of feeding an EO characterized by carvacrol, cinnamaldehyde, cineol, and pepper extract, or an antibiotic (avilamycin) on the expression of nutrient transporters and enzymes related to digestion in the intestine in broiler chickens. The expression of PepT1 and SGLT 1 were measured in the jejunum using quantitative polymerase chain reaction (qPCR). However, there were no differences in the relative mRNA expression of PepT1 or SGLT 1 in either the EO or antibiotic treatment compared to the control diet. This indicates that the improvement in performance seen when EOs are fed is likely not due to increases in PepT1 or SGLT 1 mRNA expression. Additionally, there may be differences in other nutrient transporters not investigated in this experiment. However, an upregulation in the expression of a particular gene does not always correlate to an increase in protein expression. It 
could be that any changes in nutrient transporters occur at the translational level rather than the transcriptional level. Additionally, PFAs could play a role in increasing the activity of the transporter, thereby increasing its efficiency.

\section{Effect of PFAs on intestinal morphology}

Aside from improving enzyme activity or nutrient transporter expression, PFAs are thought to elicit positive effects on the intestinal morphology of poultry, and that this may be one of the factors contributing to the increase in digestibility observed when PFAs are included in poultry diets. The intestinal wall has many finger-like projections called villi that increase the surface area for nutrient absorption. The cells which make up villi are enterocytes, and they are produced from stem cells present in the crypt, a narrow invagination between villi. These enterocytes help compose the brush border membrane, and contain microvilli which increase surface area and contain enzymes that break down nutrients (Forstner et al., 1968). A longer villus may contain more enterocytes, and digestive enzyme activity has been shown to be positively correlated with the number of enterocytes per villus (Uni et al., 1999), possibly indicating that nutrients are broken down or absorbed faster with a longer villus.

The intestinal morphology of turkey poults fed a mixture of benzoic acid and a commercial PFA (CRINA Poultry Plus®) containing EO compounds thymol, eugenol, and piperine was found to be improved compared to a control (Giannenas et al., 2014). The villus height, crypt depth, and villus height to crypt depth ratio was measured in the duodenum, jejunum, and ileum at 56 days of age. Villus height in the duodenum tended to be increased in the supplemented turkeys, and unlike the previous studies the crypt depth also tended to be increased. As such there were no differences in their ratio. The villus height was also found to be increased in both the jejunum and ileum, with no differences in the crypt depth or the villus height to crypt depth ratio. This suggests that PFAs 
may have a positive influence on the intestinal morphology of turkeys, possibly contributing to the improvements in performance and digestibility. However, as with the performance data the majority of work examining the effect of PFAs on intestinal morphology has been done in broilers.

Phytogenic feed additives have been evaluated in several studies for their effect on improving the villi height, or the villi height to crypt depth ratio in broilers. Amad and coworkers (2013) fed broilers a commercial PFA, BIOSTRONG®, with thymol and anethole as the major active substances at $150 \mathrm{mg} / \mathrm{kg}$ compared to a corn-soybean meal control. The morphology in the jejunum was evaluated at 42 days of age by recording villus height, crypt depth, and villus height to crypt depth ratio. Although not statistically significant, villus height tended to be increased with supplementation of the PFA, and crypt depth tended to be decreased by the PFA. Thus, the villus height to crypt depth ratio was significantly higher in birds supplemented with the PFA compared to the control. Another study investigated the effects of an antibiotic (avilamycin), or oregano EO at either 300 or $600 \mathrm{mg} / \mathrm{kg}$ of diet compared to a control on the morphology of the proximal jejunum in broilers (Peng et al., 2016). Unlike the previous study, there were no differences in the villus height at 42 days of age, although the crypt depth was significantly decreased in broilers fed the oregano EO at either 300 or $600 \mathrm{mg} / \mathrm{kg}$. Although the villus height to crypt depth ratio was significantly increased when broilers were fed the EO, this difference was due to a decrease in crypt depth rather than an increase in villus height. Since crypts are the source of stem cells for the villus, a shallower crypt may indicate a reduction in cell turnover, and thus an increase in performance from the energy spared from turnover (Markovic et al., 2009; Murugesan et al., 2015). Additionally, Murugesan and coworkers (2015) noted that when broilers were fed a commercial PFA (Digestarom ${ }^{\circledR}$, Biomin Holdings GmbH, Austria) villus height was increased in the jejunum and ileum by $24 \%$ and $32 \%$, respectively at 39 days of age. They also reported that mucosa 
thickness was reduced by $51 \%$ in the duodenum and $41 \%$ in the ileum, which may spare nutrients that could be available for growth.

Though there seems to be some disagreement in the literature regarding the effect of PFAs on crypt depth, villus height seems to be improved across several PFAs. A longer villus allows for an increased surface area for nutrient absorption, which may lead to improved digestibility. There is also an increase in the number of enterocytes, which may contribute to increases in brush border membrane enzyme activity. Thus, there is some evidence that PFAs may improve digestibility through the lengthening of the intestinal villus and the increase of the villus height to crypt depth ratio.

\section{Antimicrobial properties of PFAs}

Aside from improvements in digestibility and the mechanisms behind it, another proposed mode of action for the performance improvements seen when poultry are fed PFAs is the modulation of the intestinal microbiome. The GIT of poultry is home to a rich and diverse community of microbes which provide a number of benefits to the host (Zhu et al., 2002). This microbiome affects nutrition and health in addition to contributions towards the bird's carbohydrate and nitrogen metabolism (Pan et al., 2014). However, bacteria can also induce a disease state if pathogens are allowed to proliferate. For example, Clostridium perfringens can cause necrotic enteritis when allowed to grow and flourish in the intestine at the expense of microbial diversity. These negative effects are well documented and result in lower BW, inefficient use of feed, and increased mortality (Cravens et al., 2013). While antibiotics were traditionally administered to mitigate these effects, antibiotic alternatives such as PFAs continue to generate interest as producers move away from antibiotic use during production. Plant products have long 
been known for their antimicrobial properties, and as such researchers are investigating their antimicrobial effect when included in poultry diets.

McReynolds and coworkers (2009) investigated the efficacy of feeding several PFAs in reducing necrotic enteritis in broilers in two experiments. Broilers were fed a control diet or a diet containing a PFA consisting of fructooligosaccharides and EOs from citrus, oregano, and anise at varying concentrations. Lesion score, mortality, and population of $C$. perfringens were evaluated in the small intestine. The PFA significantly lowered lesion scores compared to the positive control, as well as significantly reducing mortality rate compared to the positive control but not different from the negative control that did not receive the challenge. Interestingly, in the first experiment there were no differences in the population of $C$. perfringens in the birds fed the PFA compared to the positive control, suggesting that the product is acting through a mechanism other than simply reducing the population. Similar results were found in the second experiment, although there was a significantly lower population of $C$. perfringens in the digesta. Phytogenic feed additives have been noted for their antimicrobial properties, for example peppermint and thyme EOs have been shown to reduce bacterial populations when sprayed as a mist (Witkowska et al., 2013). This suggests another potential application for PFAs to reduce pathogens in poultry houses.

While studies have demonstrated antimicrobial properties, a particular mode of action has not been reported for PFAs as a class, which may be due to the variation in chemical composition among PFAs (Brenes and Roura, 2010). However, carvacrol and thymol have been shown to disrupt the cytoplasmic membrane of Gram-negative bacteria (Xu et al., 2008). This increases the membrane permeability allowing protons and potassium to leak out of the cell leading to a loss of membrane potential and ultimately death of the cell. Si and coworkers (2005) investigated the effect of EOs on several species of pathogenic bacteria. Carvacrol, cinnamon oil, clove oil, m- 
anisaldehyde, thymol, and cinnamaldehyde all exhibited strong antibacterial activity towards Escherichia coli and Salmonella typhimurium at $500 \mu \mathrm{g} / \mathrm{mL}$. This study was, however, performed in vitro and antibacterial activity may be influenced by physiological conditions. Additionally, the inhibition of these compounds towards several Lactobacillus strains was found to be minimal, suggesting that their antimicrobial properties are selective. Carvacrol and thymol have been shown to have large zones of inhibition towards a wide variety of pathogenic bacterial species (Sokovic et al., 2010). Thus, it is likely that these compounds exhibit a broad array of effects on bacteria, as opposed to a very specific mode of action.

Several studies have investigated the effect PFAs have on the microbial community of poultry. Jamroz and coworkers (2003) demonstrated that a commercial PFA (XTRACT, XT) comprised of carvacrol, cinnamaldehyde, and capsaicin exhibited antimicrobial properties on $E$. coli and C. perfringens in the digesta of 48 day old broilers. When XT was fed at either $150 \mathrm{ppm}$ or $300 \mathrm{ppm}$, the population of E. coli was significantly reduced compared to the control. Additionally, there was no difference in the population of E. coli in birds fed XT compared to a commercial antibiotic, avilamycin. A similar effect was seen on the population of $C$. perfringens, as the birds fed XT at $300 \mathrm{ppm}$ had a significantly lower population compared to the control but not different from the birds fed avilamycin. It is noteworthy, however, that these birds were raised on clean shavings without challenge, and the effectiveness may change when there are much greater populations of bacteria present.

An EO with cinnamaldehyde and thymol as the active ingredients was shown to reduce Salmonella prevalence in challenged broilers (Amerah et al., 2012). All birds except the unchallenged control were orally-dosed with $0.1 \mathrm{~mL}$ of Salmonella Heidelberg $\left(5 \times 10^{5} \mathrm{cfu} / \mathrm{mL}\right)$ on day of hatch. Supplementation with EOs significantly reduced the percentage of Salmonella- 
positive cecal samples on day 42 compared to the challenged control by $25 \%$. Environmental Salmonella levels were determined by drag swabs, and although no significant decrease was seen between the EO treatment and the challenged control at 14 days, there was a significant reduction in the percentage of positive drag swabs at 42 days of age in the EO treatment compared to the challenged control. These data indicate that there may be a reduction in fecal shedding of birds fed PFAs, or the compounds are still active in the feces.

In contrast to antibiotics that are typically nonselective and will kill all bacteria with a susceptibility, there is evidence that PFAs do not harm, and in some cases enhance the population of beneficial intestinal bacteria. Certain species of bacteria, such as Lactobacillus, have a mutualistic relationship with the bird. These bacteria are able to obtain nutrients available in the intestine of the animal and ferment nutrients that were not fully digested or that the animal lacks the capability to digest, and yield energy in the form of volatile fatty acids that would otherwise be unavailable. Additionally, these bacteria are able to compete for attachment sites on the intestinal epithelium and competitively exclude pathogenic bacteria. Thus, it is counterproductive to kill these beneficial species of bacteria. A study by Rostami and coworkers (2015) investigated the effects of two PFAs consisting of herbs from Scrophularia striata (SS) and Ferulago angulate (FA) at either $4 \mathrm{~g} / \mathrm{kg}$ or $8 \mathrm{~g} / \mathrm{kg}$, Virginiamycin, and a control diet on the population of Lactobacillus and coliform bacteria in the jejunum, ileum, and ceca of 42 day old broilers. Although there were no differences in the population of Lactobacillus in the jejunum and ileum, SS significantly increased Lactobacillus in the ceca by $0.63 \mathrm{log} \mathrm{cfu} / \mathrm{g}$ digesta values when included at $8 \mathrm{~g} / \mathrm{kg}$, and FA significantly increased Lactobacillus by $0.59 \log \mathrm{cfu} / \mathrm{g}$ digesta values when included at $8 \mathrm{~g} / \mathrm{kg}$. However, there were no differences between the control birds and those fed SS or FA at $4 \mathrm{~g} / \mathrm{kg}$. Additionally, both SS and FA fed birds had significantly higher Lactobacillus populations 
compared to the Virginiamycin fed birds, demonstrating the antimicrobial selectivity PFAs possess compared to non-selective antibiotics. Coliform bacteria were significantly reduced by supplementation of SS or FA at either $4 \mathrm{~g} / \mathrm{kg}$ or $8 \mathrm{~g} / \mathrm{kg}$ compared to the control. An important outcome to note is that birds supplemented with SS or FA at $8 \mathrm{~g} / \mathrm{kg}$ did not have a difference in coliform bacteria populations compared to the Virginiamycin fed birds, indicating they exhibit similar antimicrobial activity.

A similar study investigated the effect of a mixture of EOs consisting of thymol, eugenol, piperine, and other flavoring substances included at $30 \mathrm{mg} / \mathrm{kg}$, or thymol included at $30 \mathrm{mg} / \mathrm{kg}$ on the population of lactic acid bacteria and coliforms in the crop, ileum, and ceca of 56 day old turkeys (Giannenas et al., 2014). Similar to the results from Rostami and coworkers (2015), there were no differences in the populations of lactic acid bacteria or coliforms in areas other than the ceca. Turkeys that were supplemented with the EO mixture had a significantly larger population of lactic acid producing bacteria in the ceca compared to the control, and a smaller population of coliforms. Surprisingly, the thymol treatment did not improve the lactic acid producing bacteria population, nor decrease the population of coliforms. This could be due to the effect of minor chemical compounds present in the mixture of EOs, or the synergism of the major and minor components when present together.

\section{Conclusions}

Based on the results of the aforementioned studies it is clear that PFAs provide a positive effect on performance when fed to poultry. The magnitude of these effects, however, depends largely on the composition of the feed additive as well as the concentration in the diet. As mentioned previously, PFA is a general term that encompasses a very broad class of compounds. Not only is the chemical composition different between plants and parts of plants, the method used 
to extract EOs plays a large role in the final concentrations. It is important to note that these chemicals give rise to the various effects seen, and in order to make accurate comparisons of PFAs the chemical makeup must be similar. The lack of an established mode of action may be due in part to the large differences between compounds fed across studies. However, it is likely that nutrient digestibility is improved upon supplementation of PFAs. This may be due to an increase in the activity of digestive enzymes or the lengthening of intestinal villi. Additionally, performance may also be improved by modulating the intestinal microbiome and GIT health. Several studies demonstrated that the intestinal microbiome can be modulated by these compounds, particularly in the distal portions of the GIT. Not only are pathogenic bacteria populations decreased, but the population of synergistic bacteria is improved both in vitro and in vivo. This leads to a more wellbalanced and diverse microbial community, improving the intestinal health of the bird. Although published data is limited on the effect of PFAs on nutrient transporter expression, it is likely that they do not function through the upregulation of PepT1 mRNA. Since mRNA expression does not always relate to protein expression, it is unclear whether PFAs influence the amount or efficiency of nutrient transporters. There is still a considerable amount of research that needs to be conducted in order to optimize the benefits of PFAs. Current research is lacking with respect to the effect PFAs have on turkeys. Although the broiler chicken and turkeys share some similarities, it is likely that there will be differences in the way PFAs function in turkeys compared to broilers. Additionally, there is a lack of research available regarding how PFAs impact diets with reduced nutrient content. If PFAs are able to compensate for a slightly reduced nutrient content, this may present an opportunity to reduce feed costs in poultry operations. Future research will need to not only investigate the ability of a PFA to improve performance, but also attempt to elicit the mechanism through which this is occurring. By determining the modes of action, the feed additive 
can be designed to contain the appropriate amount of each chemical, and can be tailored to individual producer's needs. This will allow for a very diverse class of products that are able to provide a positive impact to all facets of the poultry industry. 


\section{References}

Amad, A. A., K. Manner, K. R. Wendler, K. Neumann, and J. Zentek. 2011. Effects of a phytogenic feed additive on growth performance and ileal nutrient digestibility in broiler chickens. Poult. Sci. 90:2811-2816.

Amad, A. A., K. R. Wendler, and J. Zentek. 2013. Effects of a phytogenic feed additive on growth performance, selected blood criteria, and jejunal morphology in broiler chickens. Emir. J. Food Agric. 25:549-554.

Amerah, A. M., G. Mathis, and C. L. Hofacre. 2012. Effect of xylanase and a blend of essential oils on performance and Salmonella colonization of broiler chickens challenged with Salmonella Heidelberg. Poult. Sci. 91:943-947.

Applegate, T. J., V. Klose, T. Steiner, A. Ganner, and G. Schatzmayr. 2010. Probiotics and phytogenics for poultry: Myth or reality. J. Appl. Poult. Res. 19:194-210.

Bampidis, V. A., V. Christodoulou, P. Florou-Paneri, E. Christaki, P. S. Chatzopoulou, T. Tsiligianni, and A. B. Spais. 2005. Effect of dietary dried oregano leaves on growth performance, carcass characteristics, and serum cholesterol of female early maturing turkeys. Br. Poult. Sci. 46:595-601.

Bakkali, F., S. Averbeck, D. Averbeck, and M. Idaomar. 2008. Biological effects of essential oils-A review. Food Chem. Toxicol. 46:446-475.

Bakry, A. M., S. Abbas, B. Ali, H. Majeed, M. Y. Abouelwafa, A. Mousa, and L. Liang. 2015. Microencapsulation of oils: a comprehensive review of benefits, techniques, and applications. Compr. Rev. Food Sci. Food Saf. 15:143-182.

Betancourt, L., F. Rodriguez, V. Phandanouvong, C. Ariza-Nieto, M. Hume, D. Nisbet, G. Afanador-Tellez, A. M. Van Kley, and A. Nalian. 2014. Effect of Origanum chemotypes on broiler intestinal bacteria. Poult. Sci. 93:2526-2535.

Boruga, O., C. Jianu, C. Misca, I. Golet, A. T. Gruia, and F. G. Horhat. 2014. Thymus vulgaris essential oil: chemical composition and antimicrobial activity. J. Med. Life 7:56-60.

Bravo, D., V. Pirgozliev, and S. P. Rose. 2014. A mixture of carvacrol, cinnamaldehyde, and capsicum oleoresin improves energy utilization and growth performance of broiler chickens fed maize-based diet. J. Anim. Sci. 92:1531-1536.

Brenes, A., and E. Roura. 2010. Essential oils in poultry nutrition: Main effects and modes of action. Anim. Feed Sci. Technol. 158:1-14.

Carillon, J., F. Barbe, S. Barial, M. Sacy, and J.-M. Rouanet. 2016. Diet supplementation with a specific melon concentrate improves oviduct antioxidant defenses and egg characteristics in laying hens. Poult Sci. 95:1898-1904.

Cravens, R. L., G. R. Goss, F. Chi, E. D. De Boer, S. W. Davis, S. M. Hendrix, J. A. Richardson, and S. L. Johnston. 2013. The effects of necrotic enteritis, aflatoxin $\mathrm{B}_{1}$, and virginiamycin on 
growth performance, necrotic enteritis lesion scores, and mortality in young broilers. Poult. Sci. 92:1997-2004.

Cross, D. E., R. M. McDevitt, K. Hillman, and T. Acamovic. 2007. The effect of herbs and their associated essential oils on performance, dietary digestibility and gut microflora in chickens from 7 to 28 days of age. Br. Poult. Sci. 48:496-506.

Diaz-Sanchez, S., D. D’Souza, D. Biswas, and I. Hanning. 2015. Botanical alternatives to antibiotics for use in organic poultry production. Poult. Sci. 94:1419-1430.

Fang, Z., and B. Bhandari. 2010. Encapsulation of polyphenols- a review. Trends Food Sci. Technol. 21:510-523.

Fernandez-Alarcon, M. F., N. Trottier, J. P. Steibel, R. Lunedo, D. M. B. Campos, A. M. Santana, J. M. Pizauro, R. L. Furlan, and L. R. Furlan. 2017. Interference of age and supplementation of direct-fed microbial and essential oil in the activity of digestive enzymes and expression of genes related to transport and digestion of carbohydrates and proteins in the small intestine of broilers. Poult. Sci. 96:2920-2930.

Food and Drug Administration, Department of Health and Human Services. 2015. Veterinary Feed Directive, final rule. 21CFR parts 514 and 558. Fed. Regist. 80:31707-31735.

Gaucher, M-L., S. Quessy, A. Letellier, J. Arsenault, and M. Boulianne. 2015. Impact of a drugfree program on broiler chicken growth performance, gut health, Clostridium perfringens and Campylobacter jejuni occurrences at the farm level. Poult. Sci. 94:1791-1801.

Giannenas, I., C. P. Papaneophytou, E. Tsalie, I. Pappas, E. Triantafillou, D. Tontis, and G. A. Kontopidis. 2014. Dietary supplementation of benzoic acid and essential oil compounds affects buffering capacity of the feeds, performance of turkey poults and their antioxidant status, $\mathrm{pH}$ in the digestive tract, intestinal microbiota and morphology. Asian Australas. J. Anim. Sci. 27:225236.

Gopi, M., K. Karthik, H. V. Manjunathachar, P. Tamilmahan, M. Kesavan, M. Dashprakash, B. L. Balaraju, and M. R. Purushothaman. 2013. Essential oils as a feed additive in poultry nutrition. Adv. Anim. Vet. Sci. 2:2309-3331.

Greathead, H. 2003. Plants and plant extracts for improving animal productivity. Proc. Nutr. Soc. 62:279-290.

Hafeez, A., K. Manner, C. Schieder, and J. Zentek. 2016. Effect of supplementation of phytogenic feed additives (powdered vs. encapsulated) on performance and nutrient digestibility in broiler chickens. Poult. Sci. 95:622-629.

Hernandez, F., J. Madrid, V. Garcia, J. Orengo, and M. D. Megias. 2004. Influence of two plant extracts on broiler performance, digestibility, and digestive organ size. Poult. Sci. 83:169-174.

Hashemi, S. R., I. Zulkifli, H. Davoodi, Z. Zunita, and M. Ebrahimi. 2012. Growth performance, intestinal microflora, plasma fatty acid profile in broiler chickens fed herbal plant (Euphorbia hirta) and mix of acidifiers. 2012. Anim. Feed Sci. and Technol. 178:167-174. 
Hashemipour, H., H. Kermanshahi, A. Golian, and T. Veldkamp. 2013. Effect of thymol and carvacrol feed supplementation on performance, antioxidant enzyme activities, fatty acid composition, digestive enzyme activities, and immune response in broiler chickens. Poult. Sci. 92:2059-2069.

Jamroz, D., J. Orda, C. Kamel, A. Wiliczkiewicz, T. Wertelecki, and J. Skorupinska. 2003. The influence of phytogenic extracts on performance, nutrient digestibility, carcass characteristics, and gut microbial status in broiler chickens. J. Anim. Feed Sci. 12:583-596.

Jang, I. S., Y. H. Ko, H. Y. Yang, J. S. Ha, J. Y. Kim, S. Y. Kang, D. H. Yoo, D. S. Nam, D. H. Kim, and C. Y. Lee. 2004. Influence of essential oil components on growth performance and the functional activity of the pancreas and small intestine in broiler chickens. Asian-Aust. J. Anim. Sci. 17:394-400.

Jang, I. S., Y. H. Ko, S. Y. Kang, and C. Y. Lee. 2007. Effect of a commercial essential oil on growth performance, digestive enzyme activity and intestinal microflora population in broiler chickens. Anim. Feed Sci. and Technol. 134:304-315.

Khattak, F., A. Ronchi, P. Castelli, and N. Sparks. 2014. Effects of natural blends of essential oil on growth performance, blood biochemistry, cecal morphology, and carcass quality of broiler chickens. Poult. Sci. 93:132-137.

Lee, K.-W., H. Everts, H. J. Kappert, M. Frehner, R. Losa, and A. C. Beynen. 2003. Effects of dietary essential oil components on growth performance, digestive enzymes, and lipid metabolism in female broiler chickens. Br. Poult. Sci. 44:450-457.

Markovic, R., D. Sefer, M. Krstic, and B. Petrujkic. 2009. Effect of different growth promoters on broiler performance and gut morphology. Arch. Med. Vet. 41:163-169.

McReynolds, J., C. Waneck, J. Byrd, K. Genovese, S. Duke, and D. Nisbet. 2009. Efficacy of multistrain direct fed microbial and phytogenic products in reducing necrotic enteritis in commercial broilers. Poult. Sci. 88:2075-2080.

Mountzouris, K. C., V. Paraskevas, P. Tsirtsikos, I. Palamidi, T. Steiner, G. Schatzmayr, and K. Fegeros. 2011. Assessment of a phytogenic feed additive effect on broiler growth performance, nutrient digestibility and caecal microflora composition. Anim. Feed Sci. and Technol. 168:223231.

Murugesan, G. R., B. Syed, S. Haldar, and C. Pender. 2015. Phytogenic feed additives as an alternative to growth promoters in broiler chickens. Front. Vet. Sci. 2:21.

National Chicken Council. 2017. Per capita consumption of poultry and livestock, 1965 to estimated 2016, in pounds. Accessed July. 2017. http://www.nationalchickencouncil.org/aboutthe-industry/statistics/per-capita-consumption-of-poultry-and-livestock-1965-to-estimated-2012in-pounds/

Olobatoke, R. Y., and S. D. 2011. Mulugeta. Effect of dietary garlic powder on layer performance, fecal bacterial load, and egg quality. Poult. Sci. 90:665-670. 
Olukosi, O. A., and N. D. Dono. 2014. Modification of digesta $\mathrm{pH}$ and intestinal morphology with the use of benzoic acid or phytobiotics and the effects on broiler chicken growth performance and energy and nutrient utilization. J. Anim. Sci. 92:3945-3953.

Pan, D., and Z. Yu. 2014. Intestinal microbiome of poultry and its interaction with host and diet. Gut Microbes. 5:108-119.

Peng, Q.Y., J. D. Li, Z. Lit, Z. Y. Duan, and Y. P. Wu. 2016. Effects of dietary supplementation with oregano essential oil on growth performance, carcass traits, and jejunal morphology in broiler chickens. Anim. Feed Sci. and Technol. 214:148-153.

Pirgozliev, V., D. Bravo, M. W. Mirza, and S. P. Rose. 2015. Growth performance and endogenous losses of broilers fed wheat-based diets with and without essential oils and xylanase supplementation. Poult. Sci. 94:1227-1232.

Reisinger, N., T. Steiner, S. Nitsch, G. Schatzmayr, and T. J. Applegate. 2011. Effects of a blend of essential oils on broiler performance and intestinal morphology during coccidial vaccine exposure. J. Appl. Poult. Res. 20:272-283.

Rostami, F., H. A. Ghasemi, and K. Taherpour. 2015. Effect of Scrophularia striata and Ferulago angulate, as alternatives to virginiamycin, on growth performance, intestinal microbial population, immune response, and blood constituents of broiler chickens. Poult. Sci. 94:22022209.

Smith, J.A. 2011. Experiences with drug-free broiler production. Poult. Sci. 90:2670-2678.

Soković, M., J. Glamoclija, P. D. Marin, D. Brkić, and L. J. L. D. van Griensven. 2010. Antibacterial effects of the essential oils of commonly consumed medicinal herbs using and in vitro model. Molecules 15:7532-7546.

Si, W., J. Gong, R. Tsao, T. Zhou, H. Yu, C. Poppe, R. Johnson, and Z. Du. 2006. Antimicrobial activity of essential oils and structurally related synthetic food additives towards selected pathogenic and beneficial gut bacteria. J. Appl. Microbiol. 100:296-305.

Teixeira, B., A. Marques, C. Ramos, C. Serrano, O. Matos, N. R. Neng, J. M. F. Nogueira, J. A. Saraiva, and M. L. Nunes. 2013. Chemical composition and bioactivity of different oregano (Origanum vulgare) extracts and essential oil. J. Sci. Food Agric. 93:2707-2714.

Uni, Z., Y. Noy, and D. Sklan. 1999. Posthatch development of small intestinal function in the poult. Poult. Sci. 78:215-222.

Williams, P., and R. Losa. 2001. The use of essential oils and their compounds in poultry nutrition. World Poult. 17:14-15.

Windisch, W., K. Schedle, C. Plitzner, and A. Kroismayr. 2008. Use of phytogenic products as feed additives for swine and poultry. J. Anim. Sci. 86:E140-E148.

Witkowska, D., and J. Sowinska. 2013. The effectiveness of peppermint and thyme essential oil mist in reducing bacterial contamination in broiler houses. Poult. Sci. 92:2834-2843. 
Xu, J., F. Zhou, B.-P. Ji, R.-S. Pei, and N. Xu. 2008. The antibacterial mechanism of carvacrol and thymol against Escherichia coli. Lett. Appl. Microbiol. 47:174-179.

Ye, A., J. Cui, A. Taneja, X. Zhu, and H. Singh. 2009. Evaluation of processed cheese fortified with fish oil emulsion. Food Res. Int. 42:1093-1098.

Zhu, X. Y., T. Zhong, Y. Pandya, and R. D. Joerger. 2002. 16S rRNA-based analysis of microbiota from the cecum of broiler chickens. Appl. Environ. Microbiol. 68:124-137. 


\section{CHAPTER III}

\section{Effect of a phytogenic feed additive on turkey poult growth performance and digestibility, digestive enzyme activity, and nutrient transporter mRNA expression}

\section{ABSTRACT}

In recent years, there has been a growing interest in feeding phytogenic products to poultry for their growth and health benefits. The objective of this experiment was to determine the effects of a phytogenic feed additive on turkey poult performance over a 6-week brooding period. A total of 864 male Hybrid Converter turkey poults were obtained from a commercial hatchery and placed into pens with clean pine shavings. The three dietary treatments were randomly assigned to pens and included a corn-soy diet with no additives $(\mathbf{P C})$, a similar corn-soy diet with a $1.5 \%$ reduction in protein and key amino acids (NC), and the same NC diet with Digestarom ${ }^{\circledR}$ (PFA) included at a rate of $1 \mathrm{~g} / \mathrm{kg}$. Each experimental unit $(\mathbf{E U})$ consisted of 24 poults, with $12 \mathrm{EU}$ per treatment. Poults were provided ad libitum access to diets and water. Mortality was recorded daily, and feed disappearance and body weight were measured on days 14,28 , and 42 to determine feed intake (FI), mortality corrected feed efficiency (FE), and body weight gain (BWG). Samples were taken on days 28 and 42 to determine AMEn, crude protein digestibility (CPD), and enzyme and nutrient transporter analysis. Data were analyzed as an ANOVA with significance defined at $P \leq 0.05$ and means separated using Fisher's LSD. The PFA improved poult BWG beyond that of the PC and $\mathrm{NC}$ on day 14, and there were no differences in FE. On day 28 there were no differences in BWG among treatments, although the PC had the highest FE. The birds fed the PFA and PC diets had the highest BWG on day 42, and FE was similar to that on day 28, with the PC having the highest. No significant differences were noted for FI, AMEn, CPD, pancreatic enzyme mRNA expression, or nutrient transporter mRNA expression throughout the experiment. Data from aminopeptidase activity suggest that the PFA may be improving protein utilization. 
Key words: Body weight gain, protein sparing, enzyme activity, feed efficiency, nutrition. 


\section{INTRODUCTION}

Producers in the poultry industry are moving away from feeding antibiotic growth promoters (AGPs), which have historically been fed to enhance performance, as well as their ability to reduce clinical and subclinical disease (Applegate et al., 2010). In moving to this new production method, many producers have experienced increased FCR, decreased BWG, and significant increases in disease (Smith, 2011). As such, the industry is currently in search of alternatives to AGPs to improve FCR, BW, morbidity, and mortality. One such alternative is a class of compounds known generally as PFAs. These can be loosely defined as plant-derived products used in animal feeding (Windisch et al., 2014), and can be further differentiated into several classes including herbs, EOs, botanicals, and oleoresins (Diaz-Sanchez et al., 2015).

Current research has shown that feeding PFAs to broiler chickens has positive effects on performance (Amad et al., 2011; Mountzouris et al., 2011; Hashemipour et al., 2013; Bravo et al., 2014; Murugesan et al., 2015; Pirgozliev et al., 2015), however, research regarding how these compounds affect turkeys is limited (Bampidis et al., 2005; Mikulski et al., 2008; Giannenas et al., 2014). Although the particular mode of action of PFAs is currently unknown, several reports have attempted to elucidate potential mechanisms. Amad and coworkers (2011) showed that PFAs increase apparent ileal crude protein digestibility (CPD) in broilers at 21, 35, and 42 days of age when supplemented with a thymol and anethole containing EO. Similar effects were seen in the finisher phase of a separate experiment when broilers were fed an EO containing oregano, cinnamon, and pepper (Hernandez et al., 2004). A similar hypothesis for these improvements in performance is an increase in energy digestibility. AMEn has been shown to be improved in broilers when supplemented with turmeric meal (Olukosi and Dono, 2014), and a commercially available PFA consisting of oregano, cinnamaldehyde, and capsaicin has been shown to improve 
crude fat digestibility, although there was no effect on overall energy digestibility (Jamroz et al., 2003). Delving further into the mode of action, past research has demonstrated the ability of PFAs to increase digestive enzyme activity, which may explain the improvements in digestibility and ultimately performance (Williams and Losa, 2001). When supplemented with carvacrol and thymol, broiler trypsin and lipase activity was increased in the lumen of the duodenum (Hashemipour et al., 2013). The authors also noted similar improvements when activity was measured in the pancreas, suggesting a possible increase in enzyme production. Other studies have investigated intestinal enzymes and demonstrated that a commercial PFA composed of thymol, eugenol, and piperine increased the activity of maltase in the proximal intestine of broilers, although no differences were seen in aminopeptidase or sucrase activity (Jang et al., 2004). In contrast, aminopeptidase activity was shown to be increased in broilers when an EO containing carvacrol, cinnamaldehyde, cineol, and pepper extract was included in the diet while there were no changes in maltase activity (Fernandez-Alarcon et al., 2017). Thus, there is still debate over the effect of PFAs on digestive enzymes. Current research is limited, however, regarding the effect of PFAs in modulating the expression of genes encoding nutrient transporters and pancreatic enzymes. Fernandez-Alarcon and coworkers (2017) showed that PepT1 and SGLT 1 mRNA expression was not influenced when broilers were supplemented with a PFA consisting of carvacrol, cinnamaldehyde, cineol, and pepper extract. Additionally, little data is available on how PFAs influence other nutrient transporters along the intestinal tract, such as glucose and fructose transporters. An important point to note is that not all PFAs will function the same. As the physiological properties depends on the chemical composition, the variability in results may be related to the plant's origin, harvesting time, state of maturity, and the extraction method used to develop the PFA (Brenes and Roura, 2010). These differences in the chemical makeup may result 
in different modes of action, which may explain why a mode of action has not yet been identified. Additionally, there may be differences in the effect of PFAs between chickens and turkeys, thus requiring more research on their effect in turkeys.

Therefore, the objectives of this study were to determine the effect of a commercially available PFA (Digestarom ${ }^{\circledR}$, Biomin $\mathrm{GmbH}$ ) on the performance of turkey poults fed a reduced protein diet from day-of-hatch until 42 days of age. To elucidate possible modes of action, CPD and metabolizable energy were measured, along with the mRNA expression of several pancreatic enzymes and nutrient transporters present in the gastrointestinal tract. Finally, the activity of several digestive enzymes were measured in the small intestine.

\section{MATERIALS AND METHODS}

All animal procedures were approved by the Virginia Tech Institutional Animal Care and Use Committee. Hybrid Converter turkey poults were obtained from a local commercial hatchery and transported to Virginia Tech facilities on day-of-hatch.

\section{Experimental Design and Diets}

In this experiment, 864 male Hybrid Converter turkey poults were utilized over a 42-day experiment. Immediately upon arrival, poults were weighed and allocated to pens with 24 poults per pen. Treatments were randomly assigned to pens in a randomized complete block design. Each pen of 24 poults was an experimental unit $(\mathbf{E U})$, resulting in $12 \mathrm{EU}$ for each treatment, or 288 birds/treatment. Poults were placed into floor pens with clean pine shavings at a stocking density of $216 \mathrm{in}^{2} / \mathrm{bird}$ until 28 days of age (when 5 poults were sacrificed for sample collection) and then $225.39 \mathrm{in}^{2} / \mathrm{bird}$ until 42 days of age. Temperature was set to $30^{\circ} \mathrm{C}$ for the first week and then reduced by $1.7^{\circ} \mathrm{C}$ each week until $21^{\circ} \mathrm{C}$. Continuous lighting and supplemental heat were provided 
during the first week, and then a lighting program of 16 hours of light and 8 hours of darkness was implemented according to the Hybrid Turkeys management guide. Poults were provided ad libitum access to feed and water throughout. Birds were fed a phase I diet from day-of-hatch until 28 days of age, and then a phase II diet from 28 days of age until 42 days of age. All diets were mixed as a mash (Table 3.1). The positive control (PC) diet was formulated as an industry-type cornsoybean meal diet to meet the birds' nutrient requirements. The phase I negative control (NC) was formulated with a $1.5 \%$ reduction in crude protein, $0.06 \%$ reduction in digestible sulfur amino acids, $0.09 \%$ reduction in digestible lysine, and $0.06 \%$ reduction in digestible threonine. The phase II NC was formulated with a $1.5 \%$ reduction in crude protein, a $0.05 \%$ reduction in digestible sulfur amino acids, a $0.08 \%$ reduction in digestible lysine, and a $0.06 \%$ reduction in digestible threonine. Digestarom ${ }^{\circledR}(\mathrm{PFA})$ was mixed into the diet at a rate of $1 \mathrm{~g} / \mathrm{kg}$ of diet, and the diet had an identical nutrient profile to the NC. Digestarom $®$ is a proprietary PFA consisting of a unique blend of herbs, EOs, and functional flavors.

\section{Performance data collection}

Parameters for productive performance (body weight, body weight gain, feed intake, and feed efficiency) were measured on a bi-weekly basis throughout the experiment. Mortality was recorded daily. Feed was weighed in initially and for each addition to calculate FI. Poults were weighed as a group by pen on day-of-hatch to determine initial body weight (IBW), and then weighed as a group by pen along with feed on day 14 to determine BW, BWG, and FI. On days 28 and 42, poults were weighed individually to determine BW, and feed was weighed back to determine FI. Feed efficiency was calculated for the periods from day-of-hatch to 14 days of age, day-of-hatch to 28 days of age, and day-of-hatch to 42 days of age using BWG corrected for mortality (on a 
total pen basis with mortality weight gain added back to total pen BWG) and body weight (corrected 1 point for each $27 \mathrm{~g}$ difference from the NC), and cumulative FI.

\section{Sample collection}

On days 28 and 42, five poults per pen were randomly selected and killed by cervical dislocation. From one bird the pancreas was immediately removed, minced, and snap frozen in liquid nitrogen. The jejunum and ileum were then voided of any digesta and rinsed thoroughly with PBS. Mucosal scrapings were obtained using a microscope slide to scrape a segment from the middle of the jejunum and ileum, and samples were immediately snap frozen in liquid nitrogen. All pancreas and mucosal scrapings were stored at $-80^{\circ} \mathrm{C}$ until further use. Ileal contents from Meckel's diverticulum to the ileal-cecal junction were obtained from the remaining four birds and pooled per replicate for crude protein digestibility. Ileal contents were stored at $-20^{\circ} \mathrm{C}$ until further use. On days 28 and 40, trays with a wire-mesh top were placed in the middle of each pen to collect fresh excreta for AMEn determination. Following the removal of the trays from the pen, excreta was separated from pine shavings and stored at $-20^{\circ} \mathrm{C}$ until analysis.

\section{Nutrient digestibility}

Excreta and ileal contents collected from day 28 and 42 were dried at $65^{\circ} \mathrm{C}$ for at least 72 hours prior to being ground in a Cyclotec ${ }^{\mathrm{TM}} 1093$ sample mill with a 2-mm screen (Foss North America, Eden Prairie, MN). Nitrogen content of the feed, excreta, and ileal contents were measured using an Elementar Vario EL Cube. Approximately $20 \mathrm{mg}$ of excreta or feed were weighed in duplicate (excreta) or quadruplicate (feed) into tin capsules (Elemental Microanalysis, Devon, UK) and placed into individual sample wells in the Vario EL Cube to measure nitrogen content. 
Gross energy of excreta and feed were measured using a Parr 6400 bomb calorimeter. Approximately $0.5 \mathrm{~g}$ of excreta or feed were weighed in duplicate (excreta) or quadruplicate (feed) into stainless steel capsules (Parr Instruments Co., Moline, IL). Prior to each run the calorimeter was calibrated using a benzoic acid standard (Parr Instruments Co., Moline, IL).

Titanium analysis was conducted according to the methods described in Leone (1973). Approximately $0.3 \mathrm{~g}$ of excreta or ileal contents and $0.5 \mathrm{~g}$ of feed samples were ashed at $550^{\circ} \mathrm{C}$ for 12 hours in duplicate (ileal contents) or quadruplicate (feed). The samples were then transferred to $16 \mathrm{x} 125$ Pyrex screw cap tubes with $0.8 \mathrm{~g}$ of anhydrous sodium sulfate and digested in $5 \mathrm{~mL}$ of concentrated sulfuric acid at $73.89^{\circ} \mathrm{C}$ for at least 72 hours. Following digestion, all samples were diluted to $50 \mathrm{~mL}$. Samples were analyzed using inductively coupled plasma atomic emission spectroscopy (Spectro ARCOS SOP) at $336.121 \mathrm{~nm}$ to determine titanium concentration. AMEn was calculated individually using the following equations (Scott et al., 1982):

AMEn per g diet $=$ gross energy of diet $(\mathrm{kcal} / \mathrm{g})-[$ excreta energy per g diet $(\mathrm{kcal} / \mathrm{g})+8.22 \mathrm{x}$ nitrogen retained per $\mathrm{g}$ diet $(\mathrm{g})]$

Excreta energy per g diet $=$ gross energy of excreta $(\mathrm{kcal} / \mathrm{g}) \times\left[\mathrm{TiO}_{2}\right.$ in diet $(\%) / \mathrm{TiO}_{2}$ in excreta $(\%)]$

Nitrogen retained per $\mathrm{g}$ diet $(\mathrm{g})=$ nitrogen per $\mathrm{g} \operatorname{diet}(\mathrm{g})-$ nitrogen per $\mathrm{g}$ excreta $(\mathrm{g}) \mathrm{x}\left[\mathrm{TiO}_{2}\right.$ in diet $(\%) / \mathrm{TiO}_{2}$ in excreta $\left.(\%)\right]$

CPD was calculated individually using the following equation (Rostagno and Featherston, 1977): $\mathrm{CPD}=\left[\right.$ nitrogen in $\operatorname{diet}(\%)-$ nitrogen in sample $(\%) \times\left[\mathrm{TiO}_{2}\right.$ in $\operatorname{diet}(\%) / \mathrm{TiO}_{2}$ in sample (\%)] $/$ nitrogen in diet $(\%)$ 


\section{Nutrient transporter and pancreatic enzyme expression}

Mucosal scrapings from the jejunum and ileum, and pieces of minced pancreas were homogenized in TriReagent (Molecular Research Center Inc., Cincinnati, OH) and total RNA was extracted using the Direct-ZOL ${ }^{\circledR}$ RNA MiniPrep Kit (Zymo Research, Irvine, CA) and stored at $-80^{\circ} \mathrm{C}$ until further use. The RNA quantity and purity were determined using a Nanodrop 1000 spectrophotometer (Thermo Fisher Scientific, Waltham, MA), and samples were diluted to a concentration of $200 \mathrm{ng} / \mu \mathrm{L}$. Reverse transcription polymerase chain reaction (RT-PCR) was performed using a High Capacity cDNA Reverse Transcription Kit following the manufacturer's instructions (Applied Biosystems, Foster City, CA). Synthesized cDNA was used for qPCR with Fast SYBR ${ }^{\circledR}$ green reagent (Applied Biosystems, Foster City, CA). Samples were run in a 7500 Fast Real-time PCR instrument using the default program $\left(95^{\circ} \mathrm{C}\right.$ for $20 \mathrm{~s}, 40$ cycles of $95^{\circ} \mathrm{C}$ for 3 $\mathrm{s}$, and $60^{\circ} \mathrm{C}$ for $30 \mathrm{~s}$ ). Relative fold change was calculated using the $2^{-\Delta \Delta \mathrm{C}}$ Tethod (Livak and Schmittgen, 2001) with glyceraldehyde-3-phosphate dehydrogenase (GAPDH) serving as the reference gene. The calibrator for each gene was the day $28 \mathrm{NC}$ diet in each tissue. The genes measured as well as their function and primers are shown in Table 3.2.

\section{Intestinal enzyme activity}

Approximately $100 \mathrm{mg}$ of intestinal mucosa was weighed and homogenized in a $100 \mathrm{mM}$ mannitol $2 \mathrm{mM}$ HEPES/KOH (pH 6.5) buffer. The homogenate was then centrifuged for 10 minutes at 2,200 $\mathrm{x} \mathrm{g}\left(4^{\circ} \mathrm{C}\right)$, and the supernatant was collected and stored at $-20^{\circ} \mathrm{C}$. Protein concentration was determined using the Pierce ${ }^{\mathrm{TM}}$ BCA Protein Assay Kit (Thermo Fisher Scientific, Waltham, MA). Aminopeptidase activity was measured according to the procedure outlined by Gal-Garber and Uni (2000) using $1 \mathrm{mM}$ L-leucine-p-nitroanilide in $50 \mathrm{mM}$ phosphate buffer $(\mathrm{pH}$ 7.2) as a substrate. The homogenate and substrate were incubated at $37^{\circ} \mathrm{C}$ for $15 \mathrm{~min}$, and absorbance was 
measured at $405 \mathrm{~nm}$. One unit $(\mathbf{U})$ of leucine aminopeptidase activity is defined as the hydrolysis of $1 \mathrm{nmol}$ of L-leucine- $p$-nitroanilide in 1 minute at $37^{\circ} \mathrm{C}, \mathrm{pH}$ 7.2. The activities of maltase and sucrase were measured according to Dahlqvist (1964) using $56 \mathrm{mM}$ disaccharide in $0.1 \mathrm{M}$ maleate buffer, and glucose production was measured at $420 \mathrm{~nm}$. One $\mathrm{U}$ of disaccharidase activity is defined as the hydrolysis of $1 \mu \mathrm{mol}$ of appropriate disaccharide (maltose or sucrose) in 1 minute at $37^{\circ} \mathrm{C}, \mathrm{pH}$ 6.0. The activity of alkaline phosphatase (AP) was measured according to the methods described by Routman and coworkers (2003) using SIGMAFAST® pNPP tablets (Sigma Aldrich, St. Louis, MO). Each tablet contained $1.0 \mathrm{mg} / \mathrm{mL}$ of pNPP in $0.2 \mathrm{M}$ Tris buffer. One U of AP activity is defined as the hydrolysis of $1 \mathrm{nmol}$ of $p$-nitrophenyl phosphate in 1 minute at $37^{\circ} \mathrm{C}, \mathrm{pH}$ 10.0 .

\section{Statistical analysis}

All data were analyzed using ANOVA with significance defined at $P \leq 0.05$. Fisher's LSD test was used to separate means when ANOVA revealed a significant difference. Nutrient transporter and pancreatic enzyme mRNA expression data were analyzed as a $2 \times 3$ factorial arrangement with age and treatment as the main effects. For mortality and CPD data, analysis was performed on the $\arcsin$ of the square root of the value to normalize the data. Data points that were greater than \pm 2 SD from the mean were removed as outliers.

\section{RESULTS AND DISCUSSION}

\section{Performance}

Changes in BWG, FE, and mortality throughout the experiment are shown in Tables 3.3 and 3.4. As expected, there were no differences in IBW $(P>0.10)$. On day 14 there were no differences in 
BWG between the PC and NC fed birds, and both were approximately $3 \%$ lower than birds fed the PFA $(P=0.03)$. Despite the PFA fed birds having higher BWG, there were no significant differences in FE or FI through day $14(P>0.10)$. At this time, it cannot be concluded that performance was negatively impacted by the reduced dietary protein in the $\mathrm{NC}$ diet due to the lack of difference in BWG response between the PC and NC. Thus, it is hypothesized that the PFA may be functioning through a mechanism independent of protein. Previous literature has shown the ability of PFAs as a class to exhibit antimicrobial effects in vitro (Si et al., 2006; Xu et al., 2008) and in vivo (Jamroz et al., 2003; Amerah et al., 2012; Rostami et al., 2015). It could be that the PFA is modulating the intestinal microbiome, which is essential for the GIT development of young birds (Lilburn and Loeffler, 2015). On day 28 there were no significant differences in BWG among any treatments $(P>0.10)$, although the PC (1033 g/poult) and PFA (1038 g/poult) diets had numerically higher BWG compared to the NC (1009 g/poult). Feed intake did not differ through 28 days, and the PC had significantly higher FE (683 g/kg) compared to the NC $(662 \mathrm{~g} / \mathrm{kg})$ and PFA $(658 \mathrm{~g} / \mathrm{kg})$ diets $(P<0.01)$. On day 42 , however, the PC and PFA had approximately $4 \%$ higher BWG compared to the NC $(P<0.01)$. It is clear that by 42 days of age the reduced protein diet negatively affected the growth of poults. The addition of the PFA to the diet is thought to help compensate for the reduced protein and limiting amino acids due to the improved BWG response compared to the NC diet. Previous research has shown similar BWG improvements in turkeys, although the diets were not formulated to be deficient in any nutrient. Giannenas and coworkers (2014) showed turkey poult BWG can be increased by $7 \%$ when supplemented with a PFA containing thymol, eugenol, and piperine at $30 \mathrm{mg} / \mathrm{kg}$. There were no significant differences observed in FI through day $42(P>0.10)$, although the birds fed the PFA diet had numerically higher FI compared to both the PC and NC. Similar to the results seen on day 28, the PC had 
significantly higher FE (628 g/kg) compared to both the NC (594 g/kg) and PFA (602 g/kg) fed birds $(P<0.01)$. Although FI was not significantly different among treatments, the numerically higher FI of the birds fed the PFA could explain why the FE of birds fed the PFA diet was not significantly higher compared to the NC. Overall average mortality was $4.6 \%$ and there were no significant differences among treatments.

\section{Apparent metabolizable energy and ileal nitrogen digestibility}

Values for AMEn and CPD are shown in Table 3.5. No significant differences were observed for AMEn on day 28, although the PC and PFA tended to have a higher AMEn compared to the NC $(P=0.07)$. Again, on day 42 no significant differences were observed for AMEn $(P=0.10)$, although the PFA fed birds had numerically higher metabolizable energy (2279 kcal/kg diet) compared to the PC (2202 kcal/ $/ \mathrm{kg}$ diet $)$ and NC $(2116 \mathrm{kcal} / \mathrm{kg}$ diet $)$. These data indicate the potential for energy digestibility to be improved upon supplementation of the PFA, however, further data are needed to validate this, as the diets were formulated to be isocaloric. Overall, AMEn values were lower than expected with diets being formulated to contain $2,850 \mathrm{kcal} / \mathrm{kg}$ diet and 2,900 kcal/kg diet for the phase I and phase II diets, respectively. Additionally, values for day 42 are lower than those of day 28 which is in contrast to the formulation. This is possibly due to reasons relating to the sample collection. To collect fresh excreta, trays which contained a wiremesh top to prevent litter from entering the tray were placed on the floor of each pen for 48 hours. However, in addition to the excreta, pine shavings and feed became mixed with the excreta. Although the majority of the pine shavings were able to be separated, those that remained may have caused a dilution effect, resulting in an underestimation of AMEn. It was noted that there were considerably more pine shavings in the collection trays on day 42 compared to day 28 , which might explain why AMEn values were lower for this period. At this age the birds were larger, 
which may have made it easier for them to kick litter into the trays. Previous literature has shown varying effects with respect to PFAs on AMEn. Olukosi and Dono (2014) showed that AMEn can be improved when broilers are supplemented with turmeric meal, although Jamroz and coworkers (2003) showed that a PFA consisting of carvacrol, cinnamaldehyde, and capsaicin had no effect when included at $300 \mathrm{ppm}$.

Apparent CPD was not different at day $28(P>0.10)$, and these data follow that of the performance data at day 28 with no significant differences in BW. At day 42 the PC had higher CPD compared to the PFA, and the $\mathrm{NC}$ was intermediate $(P=0.05)$. These results were surprising as the addition of the PFA was expected to increase CPD due to the positive effect it had on BWG compared to the NC diet. However, as CPD measures the disappearance of protein from the GIT, it may not account for other factors. Several hypotheses regarding the mode of action of PFAs are an increase in endogenous secretions and the lengthening of the intestinal villi (Williams and Losa, 2001; Amad et al., 2013; Giannenas et al., 2014). If endogenous secretions are increased either by the stimulation of their release or the lengthening of the villi, resulting in more enterocytes to secrete protein, then the CPD may be disproportionately lower compared to a control. Other studies investigating the effects of PFAs in broilers have demonstrated improvements in performance, with no corresponding increase in CPD (Hernandez et al., 2004; Mountzouris et al., 2011; Pirgozliev et al., 2015). Aside from confounding effects from endogenous secretions, changes in protein digestibility may not reflect how efficient the birds are at utilizing dietary protein. It is possible that the improvements in BWG observed in this study are due to the poult's ability to utilize dietary protein more efficiently rather than increases in digestibility. More efficient utilization may spare nutrients required to maintain adequate digestion, allowing them to be allocated toward growth. 
With respect to digestible $\mathrm{CP}$ intake (Table 3.6), there were no significant differences through day $28(P>0.10)$, and birds fed the PC diet had significantly higher digestible $\mathrm{CP}$ intake compared to the NC while the PFA was intermediate $(P=0.01)$. Despite the lower protein diet, the birds fed the PFA did not have a difference in digestible CP intake compared to the PC, which may help explain the improvement in BWG observed on day 42.

\section{Nutrient transporter gene expression}

Relative gene expression for EAAT 3, PepT1, SGLT 1, and GLUT 5 in the jejunum and ileum are shown in Table 3.7. No significant interactions between age and diet were observed for any gene in either tissue. There were no treatment effects observed for any of the measured transporters in the jejunum $(P>0.10)$. An effect of age was observed for PepT1, SGLT 1, and GLUT 5 in the jejunum, with the expression of these transporters increased at day 42 compared to day 28 ( $P \leq$ 0.02). Although there were no significant treatment effects for any gene in the ileum, mRNA expression of SGLT 1 tended to be higher in birds fed the PFA, compared to both the PC and NC diets $(P=0.08)$. However, this is unlikely to be of biological significance due to the relatively small difference in fold change. A significant age effect was also seen in the ileum for EAAT 3, PepT1, and GLUT 5. The relative mRNA expression was lower at 42 days of age for EAAT 3 and PepT1 compared to day $28(P<0.01)$. GLUT 5 expression was significantly higher on day 42 compared to day $28(P<0.01)$. Although data regarding the effects of PFAs on nutrient transporters is limited, a similar study found that broilers fed an EO containing carvacrol, cinnamaldehyde, cineol, and pepper extract did not have altered PepT1 or SGLT 1 mRNA expression in the jejunum compared to the control (Fernandez-Alarcon et al., 2017). While protein production can be regulated through gene expression, it is also commonly regulated through posttranslational modifications which cannot be captured by measuring gene expression (Cooper, 
2000). Additionally, gene expression does not capture the efficiency of a transporter protein, which may be altered to spare nutrients during absorption when PFAs are added to the diet. However, it can be concluded from this study and the results of Fernandez-Alarcon that any changes in nutrient transporters might not be occurring through the regulation of gene expression.

\section{Pancreatic enzyme gene expression}

Relative gene expression for trypsin, amylase, and lipase are shown in Table 3.8. No significant interactions were observed for any gene. There was an effect of treatment on the expression of lipase in which the NC and PFA diets had significantly lower expression compared to the PC $(P<$ 0.01). This is believed to be due to modifications between the PC and NC diets where corn replaced soybean meal in the $\mathrm{NC}$ diets to generate the reduced dietary crude protein resulting in a reduction in supplemental fat (soy oil) to maintain equal energy across all three diets. An age effect was observed for trypsin and amylase in which there were significantly higher mRNA expression at 42 days of age compared to 28 days of age $(P<0.01)$. As with nutrient transporter gene expression, the production of these enzymes are commonly regulated through post-translational modifications. Additionally, not only can secretion be regulated but the activity of the enzymes in the lumen of the duodenum is regulated through proteolytic activation and co-factors. A study conducted by Hashemipour and coworkers (2013) found that trypsin, amylase, and lipase activity were increased in both the pancreas and lumen of the duodenum when broilers were supplemented with thymol and carvacrol. While enzyme and proenzyme synthesis in the pancreas seemed to be increased by PFA supplementation as evidenced by the increased activity in the pancreas, the results from this study suggest that this may not be due to an up-regulation in gene expression. 


\section{Digestive enzyme activity}

Changes in LAP specific activity are shown in Table 3.9. No differences were observed for LAP specific activity in either the jejunum or ileum at day $28(P>0.10)$. This was expected, as there were no differences in BWG at this age. However, on day 42 LAP specific activity tended to be higher in the jejunum of the NC and PFA compared to the PC diet $(P=0.10)$. It is hypothesized that this may be a compensation effect due to the reduced protein content of the diet. By increasing the activity, the bird may be able to digest more protein and amino acids, allowing for better nutrient extraction and absorption from lower protein diets. In the ileum, both the PC and PFA diets tended to have approximately $19 \%$ lower LAP specific activity compared to the NC $(P=$ 0.06). It is thought that the lower activity in the ileum of the birds fed the PFA compared to the NC may be the result of increased protein and amino acid utilization, therefore alleviating the need to increase aminopeptidase activity in the distal portions of the small intestine to scavenge any remaining protein.

The specific activity of sucrase and maltase in the jejunum and ileum are shown in Table 3.9. There were no significant differences noted in sucrase specific activity in either the jejunum or ileum at day 28 or $42(P>0.10)$. The same was true for maltase specific activity, with no significant differences seen in either tissue at either age $(P>0.10)$. Other studies investigating the effects of PFAs on broiler chickens have also observed no increase in the activity of these enzymes (Jang et al., 2004; Jang et al., 2007). These data continue to question the validity of increased AMEn with PFA feeding as another possible mechanism for increased AMEn was not improved with PFA feeding.

The specific activity of alkaline phosphatase in the jejunum and ileum are shown in Table 3.9. No significant differences were noted in the jejunum or ileum at either age. These results are 
similar to previous reports in which no change in AP activity was observed when broilers were fed PFAs (Jang et al., 2004; Jang et al., 2007). While AP has a role in digestion, particularly with regulating the intestinal absorption of lipids, it also serves a protective function (Lalles, 2010). These include regulating duodenal bicarbonate secretion and $\mathrm{pH}$, detoxifying bacterial endotoxins, and regulating the passage of bacteria through the mucosal layer. It is not particularly surprising that no differences were seen for AP, as there were no differences in AMEn and this experiment was not an induced challenge which could require the detoxification of bacterial endotoxins.

In conclusion, the PFA significantly improved turkey poult BWG at 42-days of age over that of the NC fed birds to that of the PC fed birds, suggesting a protein dependent response. The numerically higher FI for birds fed the PFA could explain why FE was not improved to that of the PC. There were no differences in AMEn among treatments, further supported by a lack of dietary treatment effect on sucrase and maltase activity, and the gene expression of nutrient transporters involved in glucose and fructose transport. While no differences in nutrient transporter or pancreatic enzyme mRNA expression were noted, qPCR data cannot fully shed light on the effect of PFAs on transport protein expression or pancreatic enzyme secretion to fully explain the increased performance noted with PFA supplementation. There were no differences in CPD, but the intermediate digestible crude protein intake and the aminopeptidase activity may suggest that the PFA is improving the efficiency of protein utilization, further supporting the increased BWG noted with the PFA fed birds. 
Table 3.1: Composition of the positive control (PC) and negative control (NC) diets of phase I fed from day-of-hatch until 28 days of age, and phase II fed from 28 days of age until 42 days of age.

\begin{tabular}{|c|c|c|c|c|c|c|}
\hline \multirow[b]{2}{*}{ Ingredient (\%) } & \multicolumn{3}{|c|}{ Phase I } & \multicolumn{3}{|c|}{ Phase II } \\
\hline & $\mathrm{PC}$ & NC & PFA & PC & NC & PFA \\
\hline Corn & 45.01 & 48.98 & 48.98 & 47.52 & 51.89 & 51.89 \\
\hline Soybean meal (48\% CP) & 40.49 & 36.39 & 36.39 & 34.89 & 31.01 & 31.01 \\
\hline Poultry byproduct meal & 5.00 & 5.00 & 5.00 & 6.00 & 6.00 & 6.00 \\
\hline Dried distillers grains + solubles & 3.00 & 3.60 & 3.60 & 5.00 & 5.00 & 5.00 \\
\hline Soy oil & 0.72 & 0.25 & 0.25 & 1.13 & 0.59 & 0.59 \\
\hline Limestone & 1.21 & 1.23 & 1.23 & 1.20 & 1.21 & 1.21 \\
\hline Dicalcium phosphate & 2.43 & 2.44 & 2.44 & 2.28 & 2.30 & 2.30 \\
\hline Salt (NaCl) & 0.25 & 0.25 & 0.25 & 0.16 & 0.16 & 0.16 \\
\hline Sodium bicarbonate & 0.10 & 0.10 & 0.10 & 0.20 & 0.20 & 0.20 \\
\hline DL-Methionine & 0.32 & 0.29 & 0.29 & 0.23 & 0.22 & 0.22 \\
\hline Lysine $\cdot \mathrm{HCl}$ & 0.36 & 0.38 & 0.38 & 0.28 & 0.31 & 0.31 \\
\hline Threonine & 0.02 & 0.01 & 0.01 & - & - & - \\
\hline Choline chloride $60 \%$ & 0.10 & 0.10 & 0.10 & 0.10 & 0.10 & 0.10 \\
\hline Vitamin and mineral premix ${ }^{1}$ & 0.75 & 0.75 & 0.75 & 0.75 & 0.75 & 0.75 \\
\hline E. coli phytase ${ }^{2}$ & 0.01 & 0.01 & 0.01 & 0.01 & 0.01 & 0.01 \\
\hline $\mathrm{TiO}_{2}$ & 0.25 & 0.25 & 0.25 & 0.25 & 0.25 & 0.25 \\
\hline Digestarom $^{\circledR}$ & - & - & 0.10 & - & - & 0.10 \\
\hline \multicolumn{7}{|l|}{ Calculated composition (\%) } \\
\hline Metabolizable energy (kcal/kg) & 2,850 & 2,850 & 2,850 & 2,900 & 2,900 & 2,900 \\
\hline Crude protein & 27.50 & 26.00 & 26.00 & 26.00 & 24.50 & 24.50 \\
\hline Digestible Methionine + Cysteine & 1.05 & 0.99 & 0.99 & 0.94 & 0.90 & 0.90 \\
\hline Digestible Lysine & 1.62 & 1.53 & 1.53 & 1.46 & 1.38 & 1.38 \\
\hline Digestible Threonine & 0.96 & 0.90 & 0.90 & 0.89 & 0.84 & 0.84 \\
\hline \multicolumn{7}{|l|}{ Analyzed composition (\%) } \\
\hline Gross energy (kcal/kg) & 3,527 & 3,452 & 3,452 & 3,532 & 3,494 & 3,494 \\
\hline Crude protein & 25.39 & 25.23 & 25.23 & 25.75 & 22.68 & 22.68 \\
\hline Titanium & 0.16 & 0.16 & 0.16 & 0.18 & 0.18 & 0.18 \\
\hline
\end{tabular}

${ }^{1}$ Provided per kg of diet: vitamin A, $6595.69 \mathrm{IU}$; vitamin $\mathrm{D}_{3}$, $2209.56 \mathrm{ICU}$; vitamin $\mathrm{E}, 1.65 \mathrm{IU}$; vitamin $\mathrm{B}_{12}$ $6.60 \mathrm{\mu g}$; menadione, $1.15 \mathrm{mg}$; riboflavin, $4.12 \mathrm{mg}$; D-pantothenic acid, $6.07 \mathrm{mg}$; niacin, $19.79 \mathrm{mg}$; choline, 381.68 mg; Co, 0.25 mg; Cu, 4.04 mg; I, 1.00 mg; Fe, 50.65 mg; Mn, 64.26 mg; Zn, 48.69 mg ${ }^{2}$ Included to reduce non-phytate phosphorous and calcium by $0.1 \%$. 
Table 3.2: Genes measured using qPCR as well as their full name, function, forward, and reverse primers.

\begin{tabular}{|c|c|c|c|c|}
\hline Gene $^{1}$ & Full name & $\begin{array}{c}\text { Accession \#/ } \\
\text { Amplicon size (bp) }\end{array}$ & Function & Forward/Reverse primers \\
\hline EAAT 3 & $\begin{array}{l}\text { Excitatory amino acid } \\
\text { transporter } 3\end{array}$ & $\begin{array}{c}\text { XM_010725627/ } \\
57\end{array}$ & $\begin{array}{c}\text { Transports glutamate } \\
\text { and aspartate }\end{array}$ & $\begin{array}{l}\text { CCCAACGCTGGACTTGTCA/ } \\
\text { CAGCTGGCAGGCCAACA }\end{array}$ \\
\hline РepT1 & Peptide transporter 1 & $\underset{58}{\text { NM_001303166/ }}$ & $\begin{array}{l}\text { Transports di- and } \\
\text { tri- peptides }\end{array}$ & $\begin{array}{l}\text { TTTGACCAGCAGGGATCGA/ } \\
\text { CAAAGTCCCCATCCATTGTTG }\end{array}$ \\
\hline SGLT 1 & $\begin{array}{l}\text { Sodium glucose linked } \\
\text { transporter } 1\end{array}$ & $\begin{array}{c}\text { XM_003211023/ } \\
58\end{array}$ & Transports D-glucose & $\begin{array}{l}\text { GGGACAGTAGGTGGATTCTTTCTG/ } \\
\text { CACCAATCGGCCACCAA }\end{array}$ \\
\hline GLUT 5 & Glucose transporter 5 & XM_010722761/ & Transports fructose & $\begin{array}{l}\text { CAACTCTCCAGCCCCCTACA/ } \\
\text { GGAGACTCCGTGCCTGTTGA }\end{array}$ \\
\hline Trypsin $^{2}$ & Pancreatic trypsin & $\begin{array}{c}\text { XM_010728045/ } \\
60\end{array}$ & Hydrolyzes peptides & $\begin{array}{l}\text { CAGTCCAAGACGGCAACGA/ } \\
\text { AGCCAGAGTGGCGGATGAC }\end{array}$ \\
\hline Amylase $^{2}$ & Pancreatic $\alpha$-amylase & XM_010715643/ & Hydrolyzes starch & $\begin{array}{c}\text { TGCCCGCCGGTACCT/ } \\
\text { CGCACTGCCTTCCTTTTGTC }\end{array}$ \\
\hline Lipase $^{2}$ & Pancreatic lipase & $\begin{array}{c}\text { XM_010714818/ } \\
60\end{array}$ & Hydrolyzes lipids & $\begin{array}{l}\text { GGCCCCAGCAATAGGACAT/ } \\
\text { CAGCCCGGCATTTCCA }\end{array}$ \\
\hline $\mathrm{GAPDH}^{2}$ & $\begin{array}{c}\text { Glyceraldehyde-3- } \\
\text { phosphate } \\
\text { dehydrogenase }\end{array}$ & $\begin{array}{c}\text { NM_001303179/ } \\
60\end{array}$ & Endogenous control & $\begin{array}{c}\text { GCCGTCCTCTCTGGCAAA/ } \\
\text { GTTCAGGTCGATGAAGGGATCA }\end{array}$ \\
\hline
\end{tabular}

${ }^{1}$ Unless otherwise noted, primers previously published by Weintraut et al., 2016.

${ }^{2}$ Primer designed by Primer Express software v3.0 (Applied Biosystems, Foster City, CA). 
Table 3.3: Initial body weight (IBW), and body weight gain (BWG) of male turkeys raised on clean pine shavings and fed a protein and AA sufficient PC, protein and AA deficient NC, or a protein and AA deficient diet supplemented with a phytogenic feed additive. ${ }^{1}$

\begin{tabular}{lcccc}
\hline Treatment: & IBW & BWG 0-14 & BWG 0-28 & BWG 0-42 \\
\hline & (g/bird) & (g/bird) & (g/bird) & (g/bird) \\
& & & & \\
Positive Control $^{2}$ & 59.1 & $252.6^{\mathrm{b}}$ & 1033 & $2460^{\mathrm{a}}$ \\
Negative Control (NC) $^{3}$ & 59.3 & $252.7^{\mathrm{b}}$ & 1009 & $2364^{\mathrm{b}}$ \\
NC+ PFA & 59.7 & $263.7^{\mathrm{a}}$ & 1038 & $2447^{\mathrm{a}}$ \\
& & & & \\
SEM & 0.31 & 3.40 & 12.89 & 21.76 \\
$P$-value & 0.34 & $\mathbf{0 . 0 4}$ & 0.25 & $<0.01$ \\
\hline
\end{tabular}

a-b Means within the same column not sharing a common superscript differ significantly $(P \leq 0.05)$.

${ }^{1}$ Values are means of 12 replicate pens of 24 turkeys.

${ }^{2}$ Positive control diet with $27.50 \%$ CP, $1.62 \%$ digestible Lys, $1.05 \%$ digestible SAA, $0.96 \%$ digestible Thr.

${ }^{3}$ Negative control similar to positive control with the exception of $\mathrm{CP}$ and AA content: $26.00 \% \mathrm{CP}, 1.53 \%$ digestible Lys, $0.99 \%$ digestible SAA, $0.90 \%$ digestible Thr.

${ }^{4} \mathrm{As}$ the NC with the addition of phytogenic feed additive (PFA) included at $1 \mathrm{~g} / \mathrm{kg}$. 
Table 3.4: Feed efficiency (FE) and cumulative mortality of male turkeys raised on clean pine shavings and fed either a protein and AA sufficient PC, protein and AA deficient NC, or protein and AA deficient diet supplemented with a phytogenic feed additive. ${ }^{1}$

\begin{tabular}{|c|c|c|c|c|c|c|}
\hline Treatment: & FE 0-14 & FE $0-28$ & FE 0-42 & $\begin{array}{c}\text { Mortality } \\
14-d\end{array}$ & $\begin{array}{c}\text { Mortality } \\
28-d\end{array}$ & $\begin{array}{c}\text { Mortality } \\
42-d\end{array}$ \\
\hline & (g/kg) & (g/kg) & (g/kg) & $(\%)$ & (\%) & (\%) \\
\hline Positive Control ${ }^{2}$ & 704 & $683^{a}$ & $628^{a}$ & 3.1 & 3.8 & 4.2 \\
\hline Negative Control $(\mathrm{NC})^{3}$ & 701 & $662^{b}$ & $594^{b}$ & 5.2 & 5.9 & 5.9 \\
\hline $\mathrm{NC}+\mathrm{PFA}^{4}$ & 706 & $658^{b}$ & $602^{b}$ & 3.5 & 3.8 & 3.8 \\
\hline SEM $^{5}$ & 6.94 & 5.48 & 4.04 & -- & -- & -- \\
\hline$P$-value & 0.85 & $<0.01$ & $<0.01$ & 0.80 & 0.89 & 0.94 \\
\hline \multicolumn{7}{|c|}{$\begin{array}{l}\text { a-b Means within the same column not sharing a common superscript differ significantly }(P \leq 0.05) \text {. } \\
{ }^{1} \text { Values are means of } 12 \text { replicate pens of } 24 \text { turkeys. } \\
2 \text { Positive control diet with } 27.50 \% \text { CP, } 1.62 \% \text { digestible Lys, } 1.05 \% \text { digestible SAA, } 0.96 \% \text { digestible Thr. } \\
{ }^{3} \text { Negative control similar to positive control with the exception of CP and AA content: } 26.00 \% \text { CP, } 1.53 \% \\
\text { digestible Lys, } 0.99 \% \text { digestible SAA, } 0.90 \% \text { digestible Thr. } \\
{ }^{4} \text { As the NC with the addition of phytogenic feed additive (PFA) included at } 1 \mathrm{~g} / \mathrm{kg} \text {. } \\
{ }^{5} \text { Analysis of mortality was on the arcsin of the square root of the value to normalize the data. }\end{array}$} \\
\hline
\end{tabular}


Table 3.5: AMEn and ileal crude protein digestibility (CPD) of male turkeys raised on clean pine shavings and fed either a protein and AA sufficient PC, a protein and AA deficient NC, or a protein and AA deficient diet supplemented with a PFA. ${ }^{1}$

\begin{tabular}{|c|c|c|c|c|}
\hline Treatment: & AMEn day 28 & CPD day 28 & AMEn day 42 & CPD day 42 \\
\hline & (kcal/kg) & $(\%)$ & (kcal/kg) & $(\%)$ \\
\hline Positive Control $^{2}$ & 2424 & 77.08 & 2202 & $74.85^{\mathrm{a}}$ \\
\hline Negative Control $(\mathrm{NC})^{3}$ & 2375 & 79.35 & 2116 & $72.83^{\mathrm{ab}}$ \\
\hline $\mathrm{NC}+\mathrm{PFA}^{4}$ & 2447 & 77.84 & 2279 & $72.40^{b}$ \\
\hline SEM $^{5}$ & 22 & - & 53 & - \\
\hline$P$-value & 0.07 & 0.20 & 0.10 & 0.05 \\
\hline
\end{tabular}

${ }^{a-b}$ Means within the same column not sharing a common superscript differ significantly $(P \leq 0.05)$.

${ }^{1}$ Values are means of 11 or 12 replicates based on sample loss or outlier analysis.

${ }^{2}$ Positive control diet with $26.00 \%$ CP, $1.46 \%$ digestible Lys, $0.94 \%$ digestible SAA, $0.89 \%$ digestible Thr.

${ }^{3}$ Negative control similar to positive control with the exception of CP and AA content: $24.50 \%$ CP, $1.38 \%$ digestible Lys, 0.90\% digestible SAA, 0.84\% digestible Thr.

${ }^{4}$ As the NC with the addition of phytogenic feed additive (PFA) included at $1 \mathrm{~g} / \mathrm{kg}$.

${ }^{5}$ Analysis of CPD was on the arcsin of the square root of the value to normalize the data. 
Table 3.6: Digestible crude protein intake of male turkeys raised on clean pine shavings and fed wither a protein and AA sufficient PC, a protein and AA deficient NC, or a protein and AA deficient diet supplemented with a PFA. ${ }^{1}$

\begin{tabular}{lcc}
\hline Treatment: & Digestible CP intake 0-28 & Digestible CP intake 0-42 \\
\hline & $(\mathrm{kg} /$ pen $)$ & $(\mathrm{kg} / \mathrm{pen})$ \\
Positive Control $^{2}$ & 6.66 & $15.40^{\mathrm{a}}$ \\
Negative Control (NC) $^{3}$ & 6.36 & $13.54^{\mathrm{b}}$ \\
$\mathrm{NC}+\mathrm{PFA}^{4}$ & 6.65 & $14.50^{\mathrm{ab}}$ \\
& & \\
SEM & 0.17 & 0.42 \\
$P$-value & 0.39 & $\mathbf{0 . 0 1}$ \\
\hline
\end{tabular}

a-b Means within the same column not sharing a common superscript differ significantly $(P \leq 0.05)$.

${ }^{1}$ Values are means of 12 replicate pens of 24 turkeys.

${ }^{2}$ Positive control diet with $26.00 \%$ CP, $1.46 \%$ digestible Lys, $0.94 \%$ digestible SAA, $0.89 \%$ digestible Thr.

${ }^{3}$ Negative control similar to positive control with the exception of CP and AA content: $24.50 \%$ CP, $1.38 \%$ digestible Lys, $0.90 \%$ digestible SAA, $0.84 \%$ digestible Thr.

${ }^{4}$ As the NC with the addition of phytogenic feed additive (PFA) included at $1 \mathrm{~g} / \mathrm{kg}$. 
Table 3.7: Relative mRNA expression of EAAT 3, PepT1, SGLT 1, and GLUT 5 in the jejunum and ileum brush border of male turkeys raised on clean pine shavings and fed either a protein and AA sufficient PC, a protein and AA deficient NC, or a protein and AA deficient diet supplemented with a PFA. ${ }^{1}$

\begin{tabular}{|c|c|c|c|c|c|c|c|c|c|}
\hline \multirow{2}{*}{$\begin{array}{l}\text { Age } \\
\text { (d) }\end{array}$} & \multirow[t]{2}{*}{ Treatment } & \multicolumn{4}{|c|}{$\longrightarrow$ Jejunum } & \multicolumn{4}{|c|}{ Ileum } \\
\hline & & EAAT 3 & PepT1 & SGLT 1 & GLUT 5 & EAAT 3 & PepT1 & SGLT 1 & GLUT 5 \\
\hline \multirow[t]{3}{*}{28} & Positive Control $^{2}$ & 0.62 & 0.99 & 0.92 & 1.00 & 0.92 & 1.05 & 0.88 & 1.02 \\
\hline & Negative Control (NC) ${ }^{3}$ & 1.10 & 0.95 & 1.02 & 1.00 & 1.11 & 1.08 & 0.96 & 1.25 \\
\hline & $\mathrm{NC}+\mathrm{PFA}^{4}$ & 0.71 & 1.18 & 0.96 & 1.06 & 0.98 & 1.25 & 0.96 & 0.96 \\
\hline \multirow[t]{3}{*}{42} & Positive Control & 0.64 & 1.17 & 1.06 & 1.20 & 0.62 & 0.72 & 0.92 & 1.97 \\
\hline & NC & 0.71 & 1.30 & 1.14 & 1.36 & 0.84 & 0.93 & 0.84 & 2.12 \\
\hline & $\mathrm{NC}+\mathrm{PFA}$ & 0.54 & 1.41 & 1.19 & 1.39 & 0.67 & 0.95 & 1.18 & 1.45 \\
\hline SEM & & 0.15 & 0.13 & 0.06 & 0.13 & 0.10 & 0.10 & 0.09 & 0.26 \\
\hline 28 & - & 0.81 & $1.04^{b}$ & $0.96^{b}$ & $1.02^{b}$ & $1.01^{\mathrm{a}}$ & $1.13^{\mathrm{a}}$ & 0.93 & $1.08^{\mathrm{b}}$ \\
\hline 42 & - & 0.63 & $1.29^{\mathrm{a}}$ & $1.13^{\mathrm{a}}$ & $1.32^{\mathrm{a}}$ & $0.71^{b}$ & $0.87^{b}$ & 0.98 & $1.84^{\mathrm{a}}$ \\
\hline SEM & & 0.09 & 0.08 & 0.03 & 0.07 & 0.06 & 0.06 & 0.05 & 0.13 \\
\hline- & Positive Control & 0.63 & 1.08 & 0.99 & 1.10 & 0.77 & 0.89 & 0.90 & 1.50 \\
\hline- & NC & 0.90 & 1.12 & 1.08 & 1.18 & 0.98 & 1.00 & 0.90 & 1.69 \\
\hline- & $\mathrm{NC}+\mathrm{PFA}$ & 0.63 & 1.29 & 1.07 & 1.22 & 0.82 & 1.10 & 1.07 & 1.20 \\
\hline \multicolumn{2}{|l|}{ SEM } & 0.10 & 0.10 & 0.04 & 0.09 & 0.07 & 0.07 & 0.06 & 0.18 \\
\hline \multicolumn{10}{|c|}{ Main Effects and Interaction Probabilities } \\
\hline \multicolumn{2}{|l|}{ Age } & 0.15 & 0.02 & $<0.01$ & $<0.01$ & $<0.01$ & $<0.01$ & 0.50 & $<0.01$ \\
\hline \multicolumn{2}{|c|}{ Treatment } & 0.11 & 0.25 & 0.21 & 0.63 & 0.10 & 0.12 & 0.08 & 0.17 \\
\hline \multicolumn{2}{|c|}{ Age $X$ Treatment } & 0.39 & 0.82 & 0.60 & 0.81 & 0.98 & 0.62 & 0.18 & 0.62 \\
\hline
\end{tabular}

a-b Means within the same column not sharing a common superscript differ significantly $(P \leq 0.05)$.

${ }^{1}$ For the interactive terms, values are means of 11 or 12 replicates due to sample loss or outlier analysis with the exception of the 42 day NC + PFA ileal GLUT 5 transporter mRNA value that was 10.

${ }^{2}$ Positive control diet with $26.00 \%$ CP, $1.46 \%$ digestible Lys, $0.94 \%$ digestible SAA, $0.89 \%$ digestible Thr.

${ }^{3}$ Negative control similar to positive control with the exception of CP and AA content: $24.50 \%$ CP, $1.38 \%$ digestible Lys, $0.90 \%$ digestible SAA, $0.84 \%$ digestible Thr.

${ }^{4}$ As the NC with the addition of phytogenic feed additive (PFA) included at $1 \mathrm{~g} / \mathrm{kg}$. 
Table 3.8: Relative mRNA expression of trypsin, amylase, and lipase in the pancreas of male turkeys raised on clean pine shavings and fed either a protein and AA sufficient PC, protein and AA deficient NC, or a protein and AA deficient diet supplemented with a PFA. ${ }^{1}$

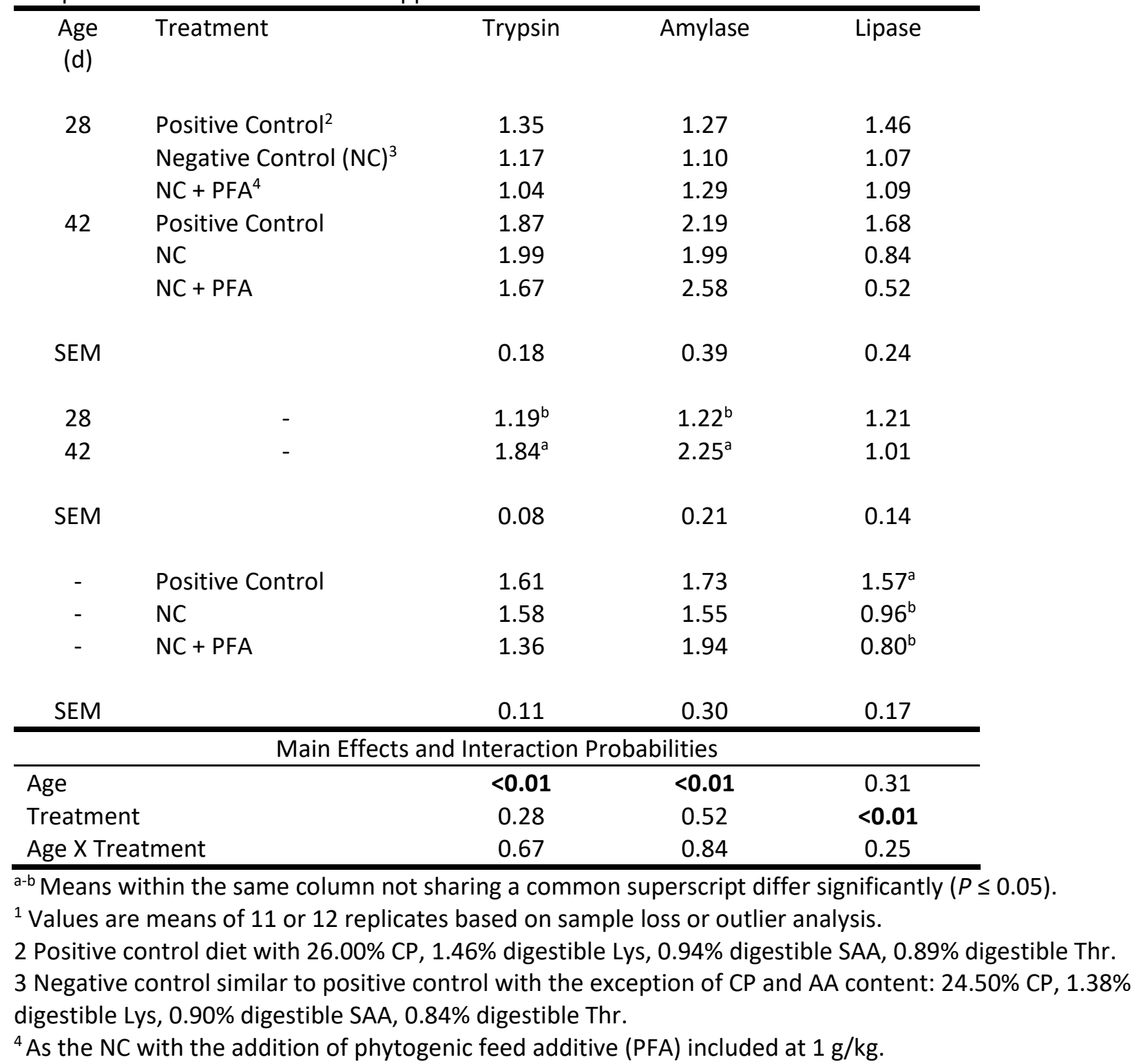


Table 3.9: Specific activity (U/mg total protein) of leucine aminopeptidase, sucrase, maltase, and alkaline phosphatase in the jejunum and ileum at days 28 and 42 of male turkeys raised on clean pine shavings and fed either a protein and AA sufficient PC, protein and AA deficient NC, or a protein and AA deficient diet supplemented with a PFA. ${ }^{1}$

\begin{tabular}{|c|c|c|c|c|}
\hline \multirow[b]{2}{*}{ Treatment: } & \multicolumn{2}{|c|}{ Jejunum } & \multicolumn{2}{|c|}{ - Ileum } \\
\hline & Day 28 & Day 42 & Day 28 & Day 42 \\
\hline & \multicolumn{4}{|c|}{ Aminopeptidase $^{2}$} \\
\hline Positive Control $^{3}$ & 8.78 & 7.06 & 13.28 & 8.69 \\
\hline Negative Control (NC) ${ }^{4}$ & 8.27 & 8.29 & 13.24 & 10.09 \\
\hline$N C+P F A^{5}$ & 8.55 & 8.24 & 12.13 & 8.29 \\
\hline SEM & 0.58 & 0.43 & 0.56 & 0.53 \\
\hline \multirow[t]{2}{*}{$P$-value } & 0.82 & 0.10 & 0.27 & 0.06 \\
\hline & \multicolumn{4}{|c|}{ Sucrase $^{6}$} \\
\hline Positive Control & 0.07 & 0.09 & 0.04 & 0.03 \\
\hline NC & 0.07 & 0.09 & 0.04 & 0.03 \\
\hline $\mathrm{NC}+\mathrm{PFA}$ & 0.07 & 0.09 & 0.05 & 0.03 \\
\hline SEM & 0.004 & 0.006 & 0.006 & 0.007 \\
\hline \multirow[t]{2}{*}{$P$-value } & 0.94 & 0.80 & 0.28 & 0.92 \\
\hline & \multicolumn{4}{|c|}{ Maltase $^{7}$} \\
\hline Positive Control & 1.00 & 1.26 & 1.08 & 0.37 \\
\hline NC & 1.03 & 1.08 & 1.04 & 0.37 \\
\hline $\mathrm{NC}+\mathrm{PFA}$ & 0.92 & 1.16 & 1.38 & 0.40 \\
\hline SEM & 0.05 & 0.07 & 0.13 & 0.05 \\
\hline \multirow[t]{2}{*}{$P$-value } & 0.28 & 0.27 & 0.13 & 0.83 \\
\hline & \multicolumn{4}{|c|}{ Alkaline Phosphatase $^{8}$} \\
\hline Positive Control & 113.00 & 107.64 & 36.80 & 22.25 \\
\hline NC & 84.23 & 97.40 & 32.13 & 25.71 \\
\hline $\mathrm{NC}+\mathrm{PFA}$ & 97.60 & 103.34 & 35.37 & 20.92 \\
\hline SEM & 9.54 & 9.10 & 4.66 & 2.17 \\
\hline$P$-value & 0.12 & 0.73 & 0.77 & 0.28 \\
\hline
\end{tabular}

${ }^{1}$ Values are means of 11 or 12 replicates based on sample loss or outlier analysis.

${ }^{2}$ One unit $(U)$ of leucine aminopeptidase activity is defined as the hydrolysis of $1 \mathrm{nmol}$ of L-leucine-pnitroanilide in one minute at $37^{\circ} \mathrm{C}, \mathrm{pH} 7.2$.

${ }^{3}$ Positive control diet with $26.00 \%$ CP, $1.46 \%$ digestible Lys, $0.94 \%$ digestible SAA, $0.89 \%$ digestible Thr.

${ }^{4}$ Negative control similar to positive control with the exception of CP and AA content: $24.50 \%$ CP, $1.38 \%$ digestible Lys, $0.90 \%$ digestible SAA, $0.84 \%$ digestible Thr.

${ }^{5}$ As the NC with the addition of phytogenic feed additive (PFA) included at $1 \mathrm{~g} / \mathrm{kg}$.

${ }^{6}$ One $\mathrm{U}$ of sucrase activity is defined as the hydrolysis of $1 \mu \mathrm{mol}$ of sucrose in one minute at $37^{\circ} \mathrm{C}, \mathrm{pH}$ 6.0 .

${ }^{7}$ One $\mathrm{U}$ of maltase activity is defined as the hydrolysis of $1 \mu \mathrm{mol}$ of maltose in one minute at $37^{\circ} \mathrm{C}, \mathrm{pH}$ 6.0 .

${ }^{8}$ One $\mathrm{U}$ of alkaline phosphatase activity is defined as the hydrolysis of $1 \mathrm{nmol}$ of $p$-nitrophenyl phosphate in one minute at $37^{\circ} \mathrm{C}, \mathrm{pH} 10.0$. 


\section{References}

Amad, A. A., K. Manner, K. R. Wendler, K. Neumann, and J. Zentek. 2011. Effects of a phytogenic feed additive on growth performance and ileal nutrient digestibility in broiler chickens. Poult. Sci. 90:2811-2816.

Amad, A. A., K. R. Wendler, and J. Zentek. 2013. Effects of a phytogenic feed additive on growth performance, selected blood criteria, and jejunal morphology in broiler chickens. Emir. J. Food Agric. 25:549-554.

Amerah, A. M., G. Mathis, and C. L. Hofacre. 2012. Effect of xylanase and a blend of essential oils on performance and Salmonella colonization of broiler chickens challenged with Salmonella Heidelberg. Poult. Sci. 91:943-947.

Applegate, T. J., V. Klose, T. Steiner, A. Ganner, and G. Schatzmayr. 2010. Probiotics and phytogenics for poultry: Myth or reality. J. Appl. Poult. Res. 19:194-210.

Bampidis, V. A., V. Christodoulou, P. Florou-Paneri, E. Christaki, P. S. Chatzopoulou, T. Tsiligianni, and A. B. Spais. 2005. Effect of dietary dried oregano leaves on growth performance, carcass characteristics, and serum cholesterol of female early maturing turkeys. $\mathrm{Br}$. Poult. Sci. 46:595-601.

Bravo, D., V. Pirgozliev, and S. P. Rose. 2014. A mixture of carvacrol, cinnamaldehyde, and capsicum oleoresin improves energy utilization and growth performance of broiler chickens fed maize-based diet. J. Anim. Sci. 92:1531-1536.

Brenes, A., and E. Roura. 2010. Essential oils in poultry nutrition: Main effects and modes of action. Anim. Feed Sci. Technol. 158:1-14.

Cooper, G.M. 2000. Protein synthesis, processing, and regulation. Chapter 7 in The cell: A Molecular Approach. $2^{\text {nd }}$ ed. Sinauer Associates, Sunderland, MA.

Dahlqvist, A. 1968. Assay of the intestinal disaccharidase. Anal. Biochem. 22:99-107.

Diaz-Sanchez, S., D. D'Souza, D. Biswas, and I. Hanning. 2015. Botanical alternatives to antibiotics for use in organic poultry production. Poult. Sci. 94:1419-1430.

Fernandez-Alarcon, M.F., N. Trottier, J.P. Steibel, R. Lunedo, D.M.B. Campos, A.M. Santana, J. M. Pizauro, R. L. Furlan, and L. R. Furlan. 2017. Interference of age and supplementation of direct-fed microbial and essential oil in the activity of digestive enzymes and expression of genes related to transport and digestion of carbohydrates and proteins in the small intestine of broilers. Poult. Sci. 96:2920-2930.

Gal-Garber, O., and Z. Uni. 2000. Chicken intestinal aminopeptidase: Partial sequence of the gene, expression, and activity. Poult. Sci. 79:41-45.

Giannenas, I., C.P. Papaneophytou, E. Tsalie, I. Pappas, E. Triantafillou, D. Tontis, and G.A. Kontopidis. 2014. Dietary supplementation of benzoic acid and essential oil compounds affects buffering capacity of the feeds, performance of turkey poults and their antioxidant status, $\mathrm{pH}$ in the digestive tract, intestinal microbiota and morphology. Asian Australas. J. Anim. Sci. 27: 225236. 
Hashemipour, H., H. Kermanshahi, A. Golian, and T. Veldkamp. 2013. Effect of thymol and carvacrol feed supplementation on performance, antioxidant enzyme activities, fatty acid composition, digestive enzyme activities, and immune response in broiler chickens. Poult. Sci. 92:2059-2069.

Hernandez, F., J. Madrid, V. Garcia, J. Orengo, and M.D. Megias. 2004. Influence of two plant extracts on broiler performance, digestibility, and digestive organ size. Poult. Sci. 83:169-174.

Jamroz, D., J. Orda, C. Kamel, A. Wiliczkiewicz, T. Wertelecki, and J. Skorupinska. 2003. The influence of phytogenic extracts on performance, nutrient digestibility, carcass characteristics, and gut microbial status in broiler chickens. J. Anim. Feed Sci. 12:583-596.

Jang, I.S., Y.H. Ko, H.Y. Yang, J.S. Ha, J.Y. Kim, S.Y. Kang, D.H. Yoo, D.S. Nam, D.H. Kim, and C. Y. Lee. 2004. Influence of essential oil components on growth performance and the functional activity of the pancreas and small intestine in broiler chickens. Asian-Aust. J. Anim. Sci. 17:394-400.

Jang, I.S., Y.H. Ko, S.Y. Kang, and C.Y. Lee. 2007. Effect of a commercial essential oil on growth performance, digestive enzyme activity and intestinal microflora population in broiler chickens. Anim. Feed Sci. Technol. 134:304-315.

Lalles, J.P. 2010. Intestinal alkaline phosphatase: multiple biological roles in maintenance of intestinal homeostasis and modulation by diet. Nutr. Rev. 68(6):323-332.

Leone, J.L. 1973. Collaborative study on the quantitative determination of titanium dioxide in cheese. J. Association of Analytical Chemists 56:535-537.

Lilburn, M.S. and S. Loeffler. 2015. Early intestinal growth and development in poultry. Poult. Sci. 94:1569-1576.

Livak, K.J., T.D. Schmittgen. 2001. Analysis of relative gene expression data using real-time quantitative PCR and the $2^{-\Delta \Delta C}$ T method. Methods. 25:402-408.

Maroux, S., D. Louvard, and J. Baratti. 1973. The aminopeptidase from hog intestinal brush border. Biochim. Biophys. Acta. 321:282-295.

Mikulski, D., Z. Zdunczyk, J. Jankowski, and J. Juskiewicz. 2008. Effects of organic acids or natural plant extracts added to diets for turkeys on growth performance, gastrointestinal tract metabolism, and carcass characteristics. J. Anim. Feed Sci. 17:233-246.

Mountzouris, K.C., V. Paraskevas, P. Tsirtsikos, I. Palamidi, T. Steiner, G. Schatzmayr, and K. Fegeros. 2011. Assessment of a phytogenic feed additive effect on broiler growth performance, nutrient digestibility and caecal microflora composition. Anim. Feed Sci. Technol. 168:223-231.

Murugesan, G.R., B. Syed, S. Haldar, and C. Pender. 2015. Phytogenic feed additives as an alternative to growth promoters in broiler chickens. Front. Vet. Sci. 2:21.

Olukosi, O.A., and N.D. Dono. 2014. Modification of digesta $\mathrm{pH}$ and intestinal morphology with the use of benzoic acid or phytobiotics and the effects on broiler chicken growth performance and energy and nutrient utilization. J. Anim. Sci. 92:3945-3953. 
Pirgozliev, V., D. Bravo, M.W. Mirza, and S.P. Rose. 2015. Growth performance and endogenous losses of broilers fed wheat-based diets with and without essential oils and xylanase supplementation. Poult. Sci. 94:1227-1232.

Rostagno, H.S., W.R. Featherston. 1977. Studies of methods to determine the availability of amino acids in chicks. Braz. J. Anim. Sci. 6(1):64-76.

Rostami, F., H. A. Ghasemi, and K. Taherpour. 2015. Effect of Scrophularia striata and Ferulago angulate, as alternatives to virginiamycin, on growth performance, intestinal microbial population, immune response, and blood constituents of broiler chickens. Poult. Sci. 94: 22022209.

Routman, K.S., L. Yoshida, A.C. Frizzas de Lima, M. Macari, J.M. Pizauro Jr. 2003. Intestinal and pancreas enzyme activity of broilers exposed to thermal stress. Braz. J. Poult. Sci. 5:23-27.

Scott, M.L., M.C. Nesheim, R.J. Young. 1982. Nutrition of the chicken. $3^{\text {rd }}$ ed. M.L. Scott \& Associates, Ithica, NY.

Si, W., J. Gong, R. Tsao, T. Zhou, H. Yu, C. Poppe, R. Johnson, and Z. Du. 2006. Antimicrobial activity of essential oils and structurally related synthetic food additives towards selected pathogenic and beneficial gut bacteria. J. Appl. Microbiol. 100:296-305.

Smith, J.A. 2011. Experiences with drug-free broiler production. Poult. Sci. 90:2670-2678.

Weintraut, M.L., S. Kim, R.A. Dalloul, and E.A. Wong. 2016. Expression of small intestinal nutrient transporters in embryonic and posthatch turkeys. Poult. Sci. 95:90-98.

Williams, P., and R. Losa. 2001. The use of essential oils and their compounds in poultry nutrition. World Poult. 17:14-15.

Windisch, W., K. Schedle, C. Plitzner, and A. Kroismayr. 2008. Use of phytogenic products as feed additives for swine and poultry. J. Anim. Sci. 86:E140-E148.

Xu, J., F. Zhou, B.-P. Ji, R.-S. Pei, and N. Xu. 2008. The antibacterial mechanism of carvacrol and thymol against Escherichia coli. Lett. Appl. Microbiol. 47:174-179. 


\section{CHAPTER IV}

\section{Conclusions}

The objective of this thesis was to investigate the effect of feeding a PFA on the performance and digestive physiology of turkey poults over a 6-week brooding period. The results generated by this work may help to uncover some of the effects PFAs have on turkey poults, as well as some of the mechanisms these compounds function through. A total of 864 male Hybrid Converter turkey poults were utilized and fed a diet consisting of a corn-soybean meal basal diet with either sufficient crude protein and limiting amino acids $(\mathbf{P C})$, reduced crude protein and limiting amino acids $(\mathbf{N C})$, or the same $\mathrm{NC}$ diet supplemented with a PFA at $1 \mathrm{~g} / \mathrm{kg}$. This is in contrast to previous studies in which PFAs were typically supplemented in a diet containing adequate nutrients and compared to a diet without the PFA, or a diet containing AGPs.

On day 14 the poults fed the diet supplemented with the PFA had significantly higher BWG compared to both the PC and NC diets. Since there were no differences between the PC and NC diets it cannot be concluded that the reduction in crude protein and amino acids caused a subsequent reduction in performance at this time. It is hypothesized that the improvement in BWG may be due to a protein-independent mechanism due to the lack of difference in analyzed protein content of the PC and NC diets. Previous literature has demonstrated the ability of PFAs to modulate the intestinal microbiome in vivo, and suggest that they possess in vitro antimicrobial effects. It could be that the PFA is helping to maintain a healthy microbial population, which in turn may either spare nutrients to allocate toward growth, or provide additional nutrients in the form of volatile fatty acids or microbial protein. In the early stage of life, the intestinal microbiome is essential for GIT development (Lilburn and Loeffler, 2015). Additionally, it is known that turkeys can be exposed to bacteria and other pathogens in the environment through a process 
known as cloacal drinking (van der Sluis et al., 2009). Thus, it is possible that poults fed the PFA may be experiencing a reduced pathogen load early in life, which may have provided a growth advantage compared to the other treatments as less nutrients would need to be allocated toward the immune system (Klasing et al., 1987). Although outside the scope of this experiment, the PFA could benefit poultry raised on dirty litter if it is able to modulate the bird's microbiome early in life when the immune system is still developing. This may provide a growth advantage to the birds when they are young, leading to subsequent improvements in bird health and performance. There were no differences in FI or FE on day 14. No significant differences in BWG were noted among treatments on day 28, although the PC and PFA diets had numerically higher BWG compared to the NC. This may be due to the similarity in analyzed CP between the PC and NC for the phase I diets. However, FE was significantly lower for the NC and PFA diets compared to the PC which may suggest the diets still had reduced limiting amino acid content. By day 42 the reduction in CP significantly reduced the performance of the poults fed the NC diet, but supplementation of the PFA improved poult BWG similar to that of the PC. Thus, it is thought that the PFA may be functioning through a protein-dependent mechanism by this age. Although there were no significant differences in FI, the PFA fed birds had numerically higher FI compared to the PC and NC groups, which may help explain why FE is not significantly higher for the PFA fed birds compared to the NC. Although there were marked differences in the composition of the diet compared to the current study, Digestarom ${ }^{\circledR}$ has previously been shown to increase BWG during the starter, grower, and finisher phases of broilers compared to a corn-soybean meal control diet (Murugesan et al., 2015). The results of the current experiment indicate the ability of the PFA to compensate for a reduction in crude protein and key amino acids of the diets of young turkeys. This may be of interest to the industry as protein is the first or second most expensive nutrient for 
least-cost formulations, and oilseed meals such as soybean meal contain anti-nutritive factors that can further reduce nutrient digestibility and performance. Thus, by reducing crude protein in the diet, feed costs can be lowered and there is potential to improve nutrient digestibility and poult performance by reducing anti-nutritive factors. Although just speculation, the improvements in poult growth early in life through feeding the PFA could translate into heavier birds throughout the production cycle and increased market weights.

It is not particularly surprising that there were no differences in AMEn considering the diets were formulated to be isocaloric. Additionally, the PFA is not thought to increase energy digestibility, and as such this experiment was designed to test its ability to improve performance under protein sparing conditions. Values for AMEn were considerably lower than expected for both time points. This is thought to be due to pine shaving contamination in the collected excreta, causing a dilution effect which underestimated AMEn. The poults fed the PFA did not have improved CP digestibility, which is somewhat contrary to previous reports as broilers supplemented with Digestarom ${ }^{\circledR}$ showed increased CP digestibility compared to a corn-soybean meal control diet (Murugesan et al., 2015). However, in the broiler experiment the diets were isonitrogenous, compared to the present study where the $\mathrm{NC}$ and $\mathrm{NC}+$ Digestarom $®$ had a $1.5 \%$ reduction in protein and key amino acid content. These different responses could be due to simple physiological differences between chickens and turkeys, or due to differences in digestibility due to limiting versus non-limiting nutrient utilization as noted above. One suggested mechanism for the performance improvement generated when poultry are fed PFAs is an increase in endogenous protein production. This may include the production or secretion of digestive enzymes such as lipase, amylase, or proteases (Applegate et al., 2010). If there is an increase in endogenous protein secretions, limitations in the apparent digestibility methodology may not detect a true increased 
digestibility. Additionally, digestibility may not fully capture changes in the ability of the bird to utilize nutrients efficiently. It could be that digestibility (mechanical, chemical, and enzymatic breakdown) is unchanged, but the bird is more efficient at utilizing dietary protein or amino acids, sparing nutrients that can be allocated toward growth. This experiment did not address how feeding PFAs affects body composition, but an improvement in protein digestibility or utilization could be reflected in an increased ratio of lean mass to fat mass. If less protein and amino acids are needed to maintain the various cells in the digestive tract, those nutrients could then be utilized to increase lean mass. It is possible that measuring the proportion of lean mass would have provided more insight as to how the PFA is impacting protein digestion than apparent digestibility alone.

Current research regarding the effect of PFAs on nutrient transporter gene expression is limited. Similar to the results of the current experiment, Fernandez-Alarcon and coworkers (2017) noted that there were no changes in PepT1 or SGLT 1 mRNA expression compared to the control when broilers were supplemented a PFA containing carvacrol, cinnamaldehyde, cineol, and pepper extract. The experiment by Fernandez-Alarcon and coworkers (2017) did not measure nutrient transporters in the ileum and Gilbert and coworkers (2007) did not measure gene expression past day 14, so it is difficult to make comparisons about the decrease in PepT1 mRNA expression in the ileum with age. There were no differences among treatments for EAAT 3, SGLT 1, or GLUT 5, which is in agreement with the work done by Fernandez-Alarcon and coworkers (2017) who found that supplementation of the PFA did not increase broiler SGLT 1 mRNA expression. Although gene expression data can certainly yield results directly relatable to performance changes, these data are limited in that they do not shed light on nutrient transporter production or transport efficiency. This experiment did not address protein expression, and it could be that more nutrient transporters are produced with no change in mRNA levels. Additionally, it is difficult to 
speculate on the efficiency of nutrient transport from gene expression data alone. If the addition of the PFA to the diet allows for nutrients to be transported into enterocytes with less expenditure, maintenance costs could be reduced resulting in more gain. Although improved efficiency may not be reflected in apparent digestibility, it could explain the improved BWG of the birds fed the PFA compared to the NC diet.

To date, no experiments investigating the effect of PFAs on pancreatic enzyme mRNA expression are available in the literature. There are, however, experiments which showed that PFAs could increase pancreatic enzyme activity in broiler chickens, particularly with trypsin and lipase (Hashemipour et al., 2013). Although there are physiological differences between chickens and turkeys, the results of the current experiment suggest that these changes may be due to regulation unrelated to transcription. Aside from transcriptional regulation, protein production is also commonly regulated by translation and post-translational modifications (Cooper, 2000). Additionally, it could be that the changes noted by Hashemipour and coworkers (2013) are due to differences in enzyme secretion from the pancreas or enzyme activation in the intestine. Although lipase mRNA expression was significantly higher in the PC compared to the NC and PFA diets, it is thought that this is due to a reduction in supplemental fat added to the NC and PFA diets compared to the PC. As supplemental fat is a major source of lipids, a reduction in this ingredient will result in less lipids to be degraded by pancreatic lipase, which may cause a downregulation of the lipase gene.

Current research regarding the effect of PFAs on digestive enzyme activity is variable. Jang and coworkers (2007) showed that total maltase activity was increased compared to the control when an EO including thymol was added to the diet at $50 \mathrm{mg} / \mathrm{kg}$. However, there were no differences in alkaline phosphatase or aminopeptidase activity. Contrary to the work by Jang and 
coworkers (2007), Fernandez-Alarcon and coworkers (2017) found that supplementation of a PFA had no effect on maltase activity, but increased the activity of alkaline phosphatase and aminopeptidase. Therefore, the literature is inconsistent in suggesting that PFAs improve the activity of these digestive enzymes, which may be due to differences in PFA composition. In the current study, the activity of aminopeptidase tended to be increased in the jejunum of birds fed the NC and PFA diets compared to the PC. This is thought to be due to the reduced dietary protein, causing an increase in enzyme activity to compensate. Interestingly, in the ileum the PC and PFA diets are similar and tend to be lower than that of birds fed the NC diet. This may be due to an improvement in protein utilization in birds fed the PFA, alleviating the need to increase enzyme activity in the distal portions of the small intestine to scavenge any remaining dietary protein. It is not surprising that no differences among treatments were found for sucrase, maltase, and alkaline phosphatase, as these enzymes are related to energy metabolism, and no significant differences in AMEn were noted. Alkaline phosphatase is a diverse enzyme and plays several roles in the digestive tract, including regulating lipid uptake and protection (Lalles, 2010). The influence of PFAs on alkaline phosphatase activity is inconsistent, with Jang and coworkers $(2004,2007)$ showing no differences across treatments, and Fernandez-Alarcon and coworkers (2017) showing that PFAs increase its activity. The results of the current study agree with those published by Jang and coworkers $(2004,2007)$, however, it must be noted that there were no changes in dietary protein across treatments in any of the previous experiments. Based on the results of the current experiment, however, it appears that reducing dietary protein and limiting amino acids did not have an effect on alkaline phosphatase activity, as there were no differences in activity between the protein sufficient PC and the reduced protein NC. 
Overall, the data generated by this experiment provides further evidence on the ability of PFAs to positively influence turkey performance, particularly BWG. Additionally, these data suggest the ability of particular PFAs to return BWG to that of an industry-type diet when dietary protein and limiting amino acids are reduced. This may provide a new direction for PFA research, as well as a potential way for producers to save money on feed costs, which represent a substantial portion of total operation costs. It would be interesting for future experiments to measure the effects of Digestarom ${ }^{\circledR}$ over the full production cycle of turkeys. Since turkeys have not maximized growth rates by 6 weeks, it could be that the feed additive will have a more substantial effect through the finisher phase. Currently few data are available which measure the effect of PFAs over the full turkey production cycle, and it is possible that the increased BWG in the early stages could provide a growth advantage to produce larger turkeys during the finishing stage. Additionally, the data from day 14 suggest that Digestarom ${ }^{\circledR}$ may help poults during the first two weeks of life, and it would be interesting to characterize changes in the intestinal microbiome at younger ages, as well as during a disease challenge. Poults fed the PFA could have more favorable microbial populations, which in turn may yield additional nutrients through microbial fermentation or protection from pathogens. If the PFA is able to help establish a favorable microbial community during the first days of life it may reduce the incidence of morbidity and mortality during a challenge with environmental pathogens. Finally, a point of future experiments could measure changes in body composition when Digestarom $®$ is included in the diet. If the PFA is functioning through a protein effect and there are not differences in apparent digestibility, it could be that there is greater lean mass compared to fat mass in birds supplemented with the PFA. An increase in the lean mass to fat mass ratio could lead to more salable product as a proportion of live weight, increasing profits. 


\section{References}

Applegate, T.J., V. Klose, T. Steiner, A. Ganner, and G. Schatzmayr. 2010. Probiotics and phytogenics for poultry: Myth or reality. J. Appl. Poult. Res. 19:194-210.

Cooper, G.M. 2000. Protein synthesis, processing, and regulation. Chapter 7 in The cell: A Molecular Approach. $2^{\text {nd }}$ ed. Sinauer Associates, Sunderland, MA.

Fernandez-Alarcon, M.F., N. Trottier, J.P. Steibel, R. Lunedo, D.M.B. Campos, A.M. Santana, J. M. Pizauro, R. L. Furlan, and L. R. Furlan. 2017. Interference of age and supplementation of direct-fed microbial and essential oil in the activity of digestive enzymes and expression of genes related to transport and digestion of carbohydrates and proteins in the small intestine of broilers. Poult. Sci. 96:2920-2930.

Gilbert, E.R., H. Li, D.A. Emmerson, K.E. Webb Jr., and E.A. Wong. 2007. Developmental regulation of nutrient transporter and enzyme mRNA abundance in the small intestine of broilers. Poult. Sci. 86:1739-1753.

Hashemipour, H., H. Kermanshahi, A. Golian, and T. Veldkamp. 2013. Effect of thymol and carvacrol feed supplementation on performance, antioxidant enzyme activities, fatty acid composition, digestive enzyme activities, and immune response in broiler chickens. Poult. Sci. 92:2059-2069.

Jang, I.S., Y.H. Ko, H.Y. Yang, J.S. Ha, J.Y. Kim, S.Y. Kang, D.H. Yoo, D.S. Nam, D.H. Kim, and C.Y. Lee. 2004. Influence of essential oil components on growth performance and the functional activity of the pancreas and small intestine in broiler chickens. Asian-Aust. J. Anim. Sci. 17:394-400.

Jang, I.S., Y.H. Ko, S.Y. Kang, and C.Y. Lee. 2007. Effect of a commercial essential oil on growth performance, digestive enzyme activity and intestinal microflora population in broiler chickens. Anim. Feed Sci. Technol. 134:304-315.

Klasing, K.C., D.E. Laurin, R.K. Peng, and D.M. Fry. Immunologically mediated growth depression in chicks: influence of feed intake, corticosterone and interleukin-1. J. Nutr. 117:1629-1637.

Lalles, J.P. 2010. Intestinal alkaline phosphatase: multiple biological roles in maintenance of intestinal homeostasis and modulation by diet. Nutr. Rev. 68:323-332.

Lilburn, M.S. and S. Loeffler. 2015. Early intestinal growth and development in poultry. Poult. Sci. 94:1569-1576.

Murugesan, G.R., B. Syed, S. Haldar, and C. Pender. 2015. Phytogenic feed additives as an alternative to growth promoters in broiler chickens. Front. Vet. Sci. 2:21.

Van der Sluis, H.J., R.M. Dwars, J.C.M. Vernooij, and W.J.M. Landman. 2009. Cloacal reflexes and uptake of fluorescein-labeled polystyrene beads in broiler chickens. Poult. Sci. 88:12421249. 